\title{
Opening the door on refrigerator energy consumption: Quantifying the key drivers in the home
}

\author{
Lloyd Harrington • Lu Aye* • Robert J. Fuller
}

Renewable Energy and Energy Efficiency Group, Department of Infrastructure Engineering, Melbourne School of Engineering, The University of Melbourne, VIC 3010, Australia

${ }^{*}$ Corresponding author

Lu Aye, ORCID:oooo-ooo2-5495-1683, <lua@unimelb.edu.au>, +61 383446879

\begin{abstract}
There is little concrete understanding of the energy consumption of refrigerating appliances during normal use or the main influences on their energy consumption. To date, no widely accepted method to disaggregate measured energy consumption measured in the home into its key components has been demonstrated. This paper examines the main external factors that impact on the energy consumption of existing refrigerating appliances in the home and how they respond to changing conditions, namely: room air temperature, defrosting behaviour and user interactions. Analysis of field data from 235 homes in Australia demonstrates that room air temperature is by far the largest factor accounting for typically around $75 \%$ of total energy consumption. Where present, energy used for defrosting is relatively small at around $10 \%$, but this does vary by household and the type of defrost controller. User interactions typically account for $15 \%$ of total energy consumed by main household refrigerating appliances, but this varies from a few percent to as much as $45 \%$ in large households. The method set out in this paper provides a basis for more in depth analysis and a better understanding of energy consumption of household refrigerators in different regions.
\end{abstract}

Keywords: Household refrigeration • User interactions • Defrosting energy $•$ Room air temperature response

Acknowledgements:

The cooperation and assistance of the 290 participating households for this research is gratefully acknowledged. The authors gratefully acknowledge the supply of field measurements for 39 appliances by Sustainability Victoria for the purpose of research and development work at the University of Melbourne. This research has been conducted within the Department of Infrastructure Engineering at the University of Melbourne, Australia and part of this research is included in the PhD thesis of Lloyd Harrington at the University of Melbourne, which has been supported by the Australian Government Research Training Program Scholarship.

Conflict of interest: The authors declare that they have no conflict of interest.

Data availability: The datasets collected and analysed are available from the corresponding author on reasonable request. 


\section{Introduction}

Household refrigeration appliances are now commonplace in developed countries and their penetration is rapidly increasing in developing countries (McNeil et al. 2008; Rao and Ummel 2017). Australia, which is by no means exceptional, currently has an ownership of household refrigerators of about 1.4 per household. Separate freezers account for a further 0.4 appliances per household (Australian Bureau of Statistics 2014). Historically, these appliances accounted for some $12 \%$ of residential electricity consumption in Australia (Energy Efficient Strategies 2008). By any measure this is a significant end use of electricity. Globally, some 150 million new household refrigerating appliances are produced every year (Euromonitor International Ltd 2017; GfK Marketing 2017). It is estimated that there were nearly 1.6 billion household products installed world-wide in 2014 and they were estimated to consume some 1,100 TWh of electricity a year (Klinckenberg Consultants 2009). This is equivalent to around $4.5 \%$ of global electricity consumption in 2014 (International Energy Agency 2016). This is consistent with data that estimates that these types of appliances in all sectors are estimated to consume as much as $6 \%$ of global electricity (Negrão and Hermes 2011).

It is therefore somewhat surprising how little is known and published about refrigerator energy consumption during normal use in the home, or the key drivers that impact on energy consumption. While there have been many end use metering campaigns over the years to measure energy of household refrigerators in the field, this data has generally provided little insight into and understanding of the main factors that affect the energy consumption of refrigerators during use.

A number of early authors have examined the energy consumption of refrigerators in test laboratories and many of these have established that room air temperature is a key driver of the energy consumption (Alissi et al. 1988; Goodson and Bullard 1994; Grimes et al. 1977; Masjuki et al. 200o; Meier and Heinemeier 1988). This has been confirmed in more recent studies, which all generally conclude that room air temperature in which the appliance operates is the most important factor that impacts on energy consumption in conditions of normal use (Anjana et al. 2015; Björk and Palm 2006; Geppert and Stamminger 2013; Hermes and Melo 2009; Hermes et al. 2009; Saidur et al. 2002; Saidur et al. 2006; Saidur et al. 2008). Many of these authors also examined the impact of user interactions such as door openings. While laboratory measurements of the energy response to changes in room air temperature are of great interest, this is of limited value unless there is good information on the temperature profiles in homes and there is a good understanding on how each appliance responds to these changes in room air temperature. Research in Europe (Geppert and Stamminger 2010) illustrated that there is a diverse range of room air temperatures in which refrigerators operate as well as a wide range of habits and practices, temperature control selection, proximity to heat sources, how full the refrigerator is during use and the thawing and cooling hot food in the refrigerator (Geppert and Stamminger 2009). Given the diversity of user habits and practices in normal use, laboratory actions devised to simulate usage in the home will not necessarily be able to cover the full range of conditions across all households. Analysis by Geppert (2011) in Europe found that as many as 50 different laboratory tests may be necessary to fully represent the full range of user interactions in homes based on current approaches.

Several previous studies have looked at the relationship between energy use in the home and compared this to energy measured under test conditions (Greenblatt et al. 2012; Meier 1995; Meier and Heinemeier 1988; Meier and Jansky 1991; Sidler et al. 2000; Zimmermann 2009; Zimmermann et al. 2012; Moretti 2000). While many of these studies have found that, on average, laboratory conditions appear to result in a measured energy consumption that was similar to that measured in homes, the underlying data shows substantial variations from household to household without any underlying explanation as to the key drivers of the observed variability. A review paper by the Market Transformation 
Programme (2007) looked at a range of studies that compared in-home measurements with energy values measured in test laboratories with a view to making test procedures more representative. It noted that several studies found that room air temperature has a strong impact and freezer control setting is also important. The review paper also looked at laboratory studies where the energy impact of door openings was quantified and concluded that the impact was only small (a few percent). But none of the studies examined measured additional cooling energy for food and drinks during normal use and it also noted the divergent defrost behaviour between the test laboratory and in the home.

Only a limited number of papers have attempted to analyse energy consumption data measured in the field to establish those factors that influence energy consumption. An early paper (Gage 1995) recorded information on door openings and kitchen temperature and found that both of these factors appeared to influence energy consumption. However, the sample was small - only nine households - but the methodology used was promising. Saidur et al. (2006) used segmentation analysis of 30 households to estimate the impact of more frequent door openings on energy consumption, compartment control settings and exposure to a heat source. The paper concluded that each of these factors was significant, but there were limitations on the quantification of these impacts due to the binary nature of the variables reported and the analysis approach. A later paper (Saidur et al. 2008) covered 104 refrigerators and used a similar approach but looked at door openings, exposure to heat sources and appliance size. While the paper also found each of these parameters had a significant impact on the measured energy consumption, quantification of the influence of these factors was limited by the binary nature of the input variables (small or large volume, exposure or not to a heat source). Other limitations were that the study was conducted in Malaysia and it appeared that all houses were very warm most of the time, items that were classified as heat sources were quite variable (oven, rice cooker, microwave, kettle, etc.) and self-reporting was used to quantify door openings. There could be significant self-bias in reporting some behavioural aspects, like door openings, which may be viewed as pro-environmental (Brenner and DeLamater 2014; Steg and Vlek 2009; Whitmarsh 2009).

The advent of moderate cost and accurate energy and temperature data loggers means that it is now easier than ever to collect energy data for refrigerators in the home. However, analysis of this data is notoriously complex and field data collected in homes has been very difficult to interpret. Houses in Australia exhibit significant seasonal changes in indoor temperatures over the year and significant diurnal changes are common (Harrington et al. 2015), although the range and variability of indoor temperatures will be regionally specific. Seasonal changes will be less important in countries where central heating and cooling is prevalent, but room air temperature still plays an important role. A second factor is that user interactions induce significant additional energy consumption in refrigerating appliances. While this interaction does appear to have some broad pattern in terms of seasonality in most houses, in general terms, user interactions are highly variable from day-to-day. While door openings do appear to make up an important part of user-induced energy consumption, cooling of food and drink also makes up a substantial part of this element. A third factor making raw data difficult to interpret is that many modern household refrigeration appliances have an automatic defrost system, and therefore defrost and recovery events are interspersed throughout the data.

\section{Background - operational basics of refrigerators}

In its simplest manifestation, a refrigerator or freezer is an insulated box to which is attached a heat pump. Almost all household refrigerating appliances use a heat pump that uses the vapour-compression cycle, as other cooling technologies are poorly developed or very inefficient (Bansal et al. 2011). The heat pump consists of a compressor, a condenser, an expansion control system (typically capillary tubes for household style refrigerators (Dubba 
and Kumar 2017), but may be a valve) and an evaporator, all connected in a loop and filled with an appropriate charge of refrigerant. The heat pump collects energy from inside the refrigerator and rejects it to the room space using the vapour compression cycle (or Carnot refrigeration cycle). Under steady state conditions, the heat gain through the walls and door seals of the appliances is balanced by the heat extracted and rejected by the refrigeration system to the room.

The majority of refrigerators globally still use a single speed compressor, which effectively has two states: compressor "on" or "off". In steady state operation, these appliances usually exhibit a consistent compressor cycle duration and percentage run-time. As the room air temperature increases, the percentage run-time increases to compensate for the additional heat gain. Inverter driven systems are common in Japan and are increasing in popularity in different regions. Inverter systems also cycle "on" and "off" under some operating conditions but may also step between different power levels in order to maintain compartment temperatures.

The new International Electrotechnical Commission (IEC) test method (IEC62552-3 2015) includes energy tests at ambient temperatures of $16^{\circ} \mathrm{C}$ and $32{ }^{\circ} \mathrm{C}$, which allows different regions to weight each energy consumption value in a way that provides a better estimate of the likely energy consumption under conditions of normal use in different regions. As this standard is implemented in more countries, the operating efficiency of inverter-driven systems at lower ambient temperatures, which are common in many regions, should be recognised and their prevalence is likely to increase, particularly where the energy consumption value at $16{ }^{\circ} \mathrm{C}$ is more heavily weighted in the assessment of product efficiency.

Refrigerators have a temperature control system (previously simple thermostats, but now more commonly electronic controls) that maintains internal compartment temperatures within a relatively narrow range. Most appliances allow the user to adjust the compartment temperature within defined limits. Appliances with good temperature control capability can maintain fairly constant compartment temperatures even when the surrounding room air temperature varies substantially. For products with poor control, the compartment temperatures may drift from the set point when there is a significant change in room air temperature, which may prompt the user to adjust controls.

Refrigerating appliances may have a number of other features and functions. Fans and small heaters are common and their energy consumption is included in the overall measured value of energy consumption. Depending on how they are configured, the operation of heaters may impact on the overall system efficiency. Some heaters vary their energy consumption depending on ambient conditions and, in some cases, the level of user interaction.

\section{Method}

\subsection{Overview}

This paper provides a fresh and new approach to the analysis of refrigerator energy data measured in homes. It documents a method that can be readily adopted by analysts to split the measured energy into three key components: temperature-driven energy consumption, defrosting energy consumption and user-induced energy consumption. Information on defrost frequency is also derived. The method is generic and can be applied to high quality energy and temperature data collected from houses in any region. The approach builds on knowledge and information on how refrigerators work and how they are typically tested in a laboratory. However, there are several new and innovative data analysis steps that have been especially developed to handle data measured in the home. The advantage of this approach is that it quantifies each of the elements separately. This will allow more complex investigations on the influence room air temperature and household demographics on defrost performance (defrost energy and defrost interval) and the user-induced energy consumption. Analysing field data in this manner provides a means of quantifying user impacts directly, which is much more 
accurate than assessing a range of arbitrary user actions simulated in a test laboratory. The results of applying this method to 235 refrigerating appliances measured in houses around Australia provides a much deeper insight into the range of normal use and how each of these elements impacts on the energy consumption for each individual appliance.

Many aspects of refrigerator design can influence its energy consumption such as insulation thickness and its effectiveness, compressor efficiency and controls. While conditions of use and user interactions vary a lot by household, it is important to remember that once a refrigerator has been constructed and installed in a home, its energy attributes, such as its response to ambient temperature, its defrosting control algorithm and the efficiency with which it removes user heat loads, is largely fixed. The method documented allows the energy consumption of different appliances in the same home to be compared in an objective manner and also allows the energy consumption of the same appliance in different homes to be estimated. This is an important step forward for policy analysts as they look at improving test methods to better reflect normal use in test procedures.

For this project, high quality energy consumption and room air temperature data were collected from 250 appliances in homes covering five very different climatic zones on the east coast of Australia, from Melbourne to Cairns. Households were primarily recruited through snowball recruitment as well as through media, electricity utilities and product suppliers. Portable programmable data loggers were used to record average power data each minute during the monitoring period. For some sites, data was collected at 2 min intervals, which provided equivalent resolution of compressor cycles. Data loggers used an internal battery to maintain the correct time if there was a power outage. Ambient air temperature in the room was recorded using battery-powered programmable temperature data loggers. The manufacturer specifications (OmegaWatt 2008) for the power and temperature measuring instruments were:

- energy meter: active power from $2 \mathrm{~W}$ to $3000 \mathrm{~W} \pm 1 \%$

- temperature meter: $-20{ }^{\circ} \mathrm{C}$ to $+105{ }^{\circ} \mathrm{C} \pm 0.5{ }^{\circ} \mathrm{C}$.

After analysis of the data, it was found that 15 appliances included in the original analysis had serious problems or were faulty, so these were removed from the overall data set. This left a total of 235 units. The age of appliances was broadly representative of the installed stock of appliances in Australia and ranged from new to over 30 years old. A later section sets out the results from analysing the field data by processed it using the method set out in this section.

\subsection{Considerations during the collection of field data}

In practical terms, it is not possible to collect data at $1 \mathrm{~s}$ intervals for a period of months or years where data is stored internally, as most data loggers have limited storage memory capacity. Continuous or periodic data upload options are now more available through a range of telemetry systems, which usually eliminates data storage limitations. Most refrigerator test procedures require a sampling interval of $1 \mathrm{~min}$ or less so this data interval is also sufficient for field measurements. For field measurements where data is stored in the logger, a practical conflict exists between a longer interval, that will increase the time before the memory is full, against a shorter interval, that allows better definition of individual compressor cycles. Experience with a large number of appliances has shown that intervals of 1 min or 2 min allow individual compressor cycles and other events, such as defrost heaters, to be clearly and accurately discerned and provides a reasonable monitoring period before data download from loggers is required. Ideally, data collected during each interval should be average power or energy-based measurements with an equivalent resolution of $0.01 \mathrm{Wh}$ or better.

Room air temperature is a critical determinant of the energy consumption of refrigeration appliances. Surprisingly, many field studies do not appear to collect room air temperature data, so this makes in-depth analysis of that field data almost impossible. Academic literature and experience with the analysis of field data in Australia have shown that 
room air temperature is by far the most important influence of refrigerator energy consumption in the home. Temperature sensors need to be placed in a position that provides a representative measure of the room air temperature that the appliance will experience. Care is required to avoid radiant heat sources (cooking appliances, heaters, the refrigerator itself, sunlight) and sinks (windows, air conditioning equipment).

\subsection{Separation of data into compressor cycles}

Due to the cycling of compressors, the short term power and energy consumption of an operating refrigerator is continually varying. Refrigerator test procedures have traditionally broken energy data up into compressor cycles as this provides a much clearer indication of the average work being undertaken by the refrigeration system over time. Each compressor cycle is examined individually in order to calculate its average power ${ }^{1}$. For products with a regular pattern of compressor cycles, the average power per compressor cycle remains quite stable in a test room with a constant temperature.

The length of compressor cycles on typical refrigerating appliances varies from around $20 \mathrm{~min}$ to as long as $100 \mathrm{~min}$ under steady state operating conditions, depending on the product design and configuration. Typical compressor power when "on" ranges from $80 \mathrm{~W}$ to more than $300 \mathrm{~W}$, depending on the size and age of the appliance. Newer appliances tend to have much lower power input because the efficiency of compressors has increased markedly over the past 20 years.

In order to break data into compressor cycles for this project, an extensive period of the raw data was examined for each appliance to ascertain the typical power of the compressor and also auxiliaries such as the defrost heater (if present). Using average power for the data logged before and after each compressor start, the start time for each compressor cycle was interpolated. A similar calculation was also undertaken to determine the compressor stop time. The start and stop time in each compressor cycle is used to calculate the average input power when the compressor is "on" and "off" within each compressor cycle. This process was automated through the selection of thresholds between compressor "on" and "off" and between defrost heater "on" and "off" for each individual appliance. Software was written to calculate the following parameters for each compressor cycle:

- compressor start date and time interpolated to the second,

- average cycle power $(\mathrm{W})$,

- average "on" power (W) and average "off" power (W),

- cycle length (mins) and \% time "on" and \% time "off",

- energy (Wh),

- type of cycle (normal compressor, defrost heater, or cycle adjacent to the defrost heater),

- room air temperature (typically this is recorded on a separate device on a separate time interval so data needs to be merged and averaged for each compressor cycle).

Given that most sites were measured for at least six months and had data collected at 1 min intervals, this represents a formidable amount of data to process (typically over 200,000 records per site). The software developed allowed each site to be fully processed into compressor cycles in less than one minute. Having reliable and fast software to analyse compressor cycles is a key component of the analysis process.

Defrost heater operation can usually be readily identified as the average "on" power is significantly different to the compressor power (usually higher). Some Asian products have a defrost heater power that is similar to the compressor power. In these cases, manual separation of the data was necessary, noting that this is very laborious where months of 1 min

\footnotetext{
${ }^{1}$ By convention, compressor cycles are usually defined from compressor "on" until the subsequent compressor "on". Defrost heater cycles are normally defined from the defrost heater "on" until the subsequent compressor "on".
} 
data is involved. Cycles that included a power supply outage were readily identified by an abnormally low percentage run-time and very long compressor "off" time for the measured room air temperature. The compressor "on" time for the cycle following a power outage was usually much longer than normal to recover back to steady state conditions. During analysis, cycles with a power outage and the following recovery cycle were excluded as they do not give an accurate impression of normal use. Once the data was processed in this fashion, it was ready for more detailed analysis and disaggregation.

\subsection{Refrigeration appliance response to room air temperature}

While it is well-known and understood that the room air temperature will have a significant impact on the energy consumption of a refrigerating appliance, there is surprisingly little data in the public domain on this topic. A range of authors have examined the temperature response of a handful of refrigerator models in the test laboratory setting (Alissi et al. 1988; Anjana et al. 2015; Geppert and Stamminger 2013; Grimes et al. 1977; Koa and Kelly 1996; Saidur et al. 2002) but these authors have not established any generalised response in energy to changes in room air temperature. One of the major issues is that, until recently, most regional test procedures have only tested energy consumption at a single ambient temperature so data across different temperatures have not been routinely collected. As different refrigerating appliance types and configurations respond to changes in room air temperature differently, comparison of energy consumption is generally only valid at the temperature in which the measurement was made. To illustrate this, the change in steady state power with changes in ambient temperature for some typical appliances as measured in a test laboratory are illustrated in Fig. 1. A comprehensive assessment of changes in energy consumption for household refrigerating appliances in response to changes in room air temperature for a range of different refrigerating appliances is given in Harrington et al. (2018b).

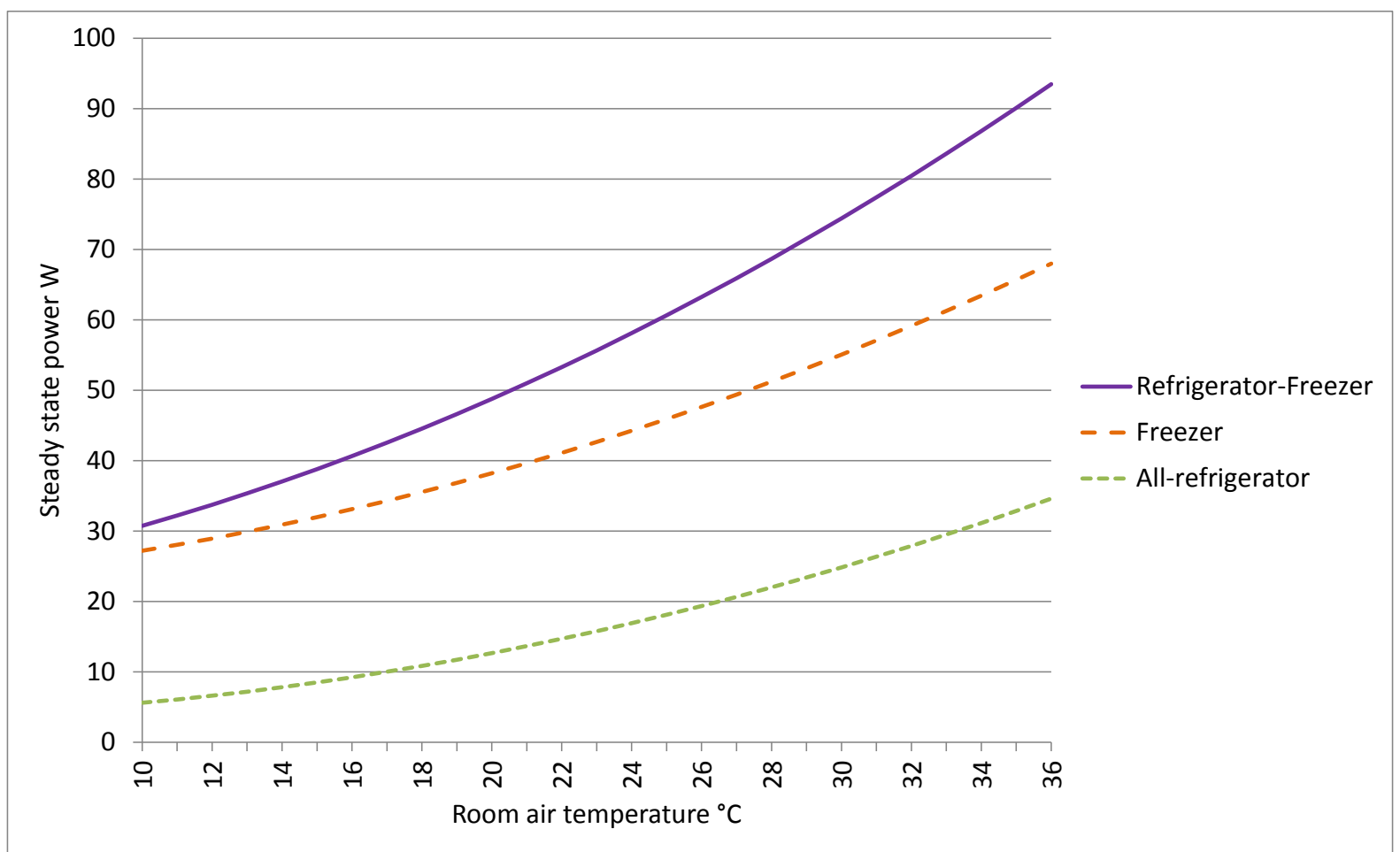

Fig. 1: Changes in average power with changes in room air temperature - typical products (Source: Laboratory data from Australian Consumers' Association (2012) and author analysis. In the case where an appliance cycles, the steady state power is the average power over a number of whole compressor cycles.) 
The heat gain through the walls of a refrigerator (including all sides exposed to ambient air and door seals) is a function of the insulation effectiveness (thermal transmittance or $U$ value), surface area and the overall temperature difference between the internal compartment temperature and the room air temperature surrounding the refrigerator. The heat gain into each compartment is therefore a linear function of temperature difference between the compartment and the room (assuming constant thermal transmittance), which means that the total appliance heat load is a linear function of room air temperature because compartment temperatures are quite constant. However, the coefficient of performance (COP) of the whole refrigeration system is also affected by the condensing temperature (which is dictated by the room air temperature), so the efficiency of the refrigeration system declines as the room air temperature increases (Harrington et al. 2018b). This explains why the steady state power increases at a rate that is faster than linear when the room air temperature increases and why the steady state power as a function of temperature appears to be a gentle curve. This simplified description has been included to explain the underlying factors that drive refrigerator energy consumption. Reality is more complex as there are often heaters, electronics and other auxiliaries that can affect both energy consumption and heat gain and many of these will not be a function of room air temperature. A more detailed mathematical model of heat gain into a refrigerating appliance is given by Gupta et al. (2007).

Information on the power response to changes in ambient temperature is not readily available and this type of data is somewhat unique to every model. Fortunately, the method proposed to analyse field data generates a unique curve of room air temperature versus average power where there is sufficient data (typically four to six weeks of data is a minimum to obtain robust results). With the raw data split into individual compressor cycles, it is then possible to undertake detailed analysis. The first step is to undertake an X-Y plot of room air temperature versus average cycle power for the whole monitoring period. When plotted as a scatter chart, the average power per cycle appears as a cloud. Usually there are three (or four) distinct clouds of data:

1. Upper Cloud - defrost heater operation (constant across temperatures),

2. Intermediate Cloud 1 - compressor cycles immediately before a defrost - this is generally close to the compressor "on" power as there is only a short "off" time, if any (fairly constant across temperatures),

3. Intermediate Cloud 2 - recovery periods after a defrost (increases with warmer room air temperature),

4. Lower Cloud - normal usage with some or no user interaction (increases with warmer room air temperature).

Clouds 1, 2 and 3 only appear in refrigerating appliances with an automatic defrost system. An example of a monitored refrigerator in an Australian home over one year is depicted in Fig. 2. Note that only average power for each cycle is plotted - the length of the compressor cycle or heater cycle for each point would be required to calculate the associated energy. 


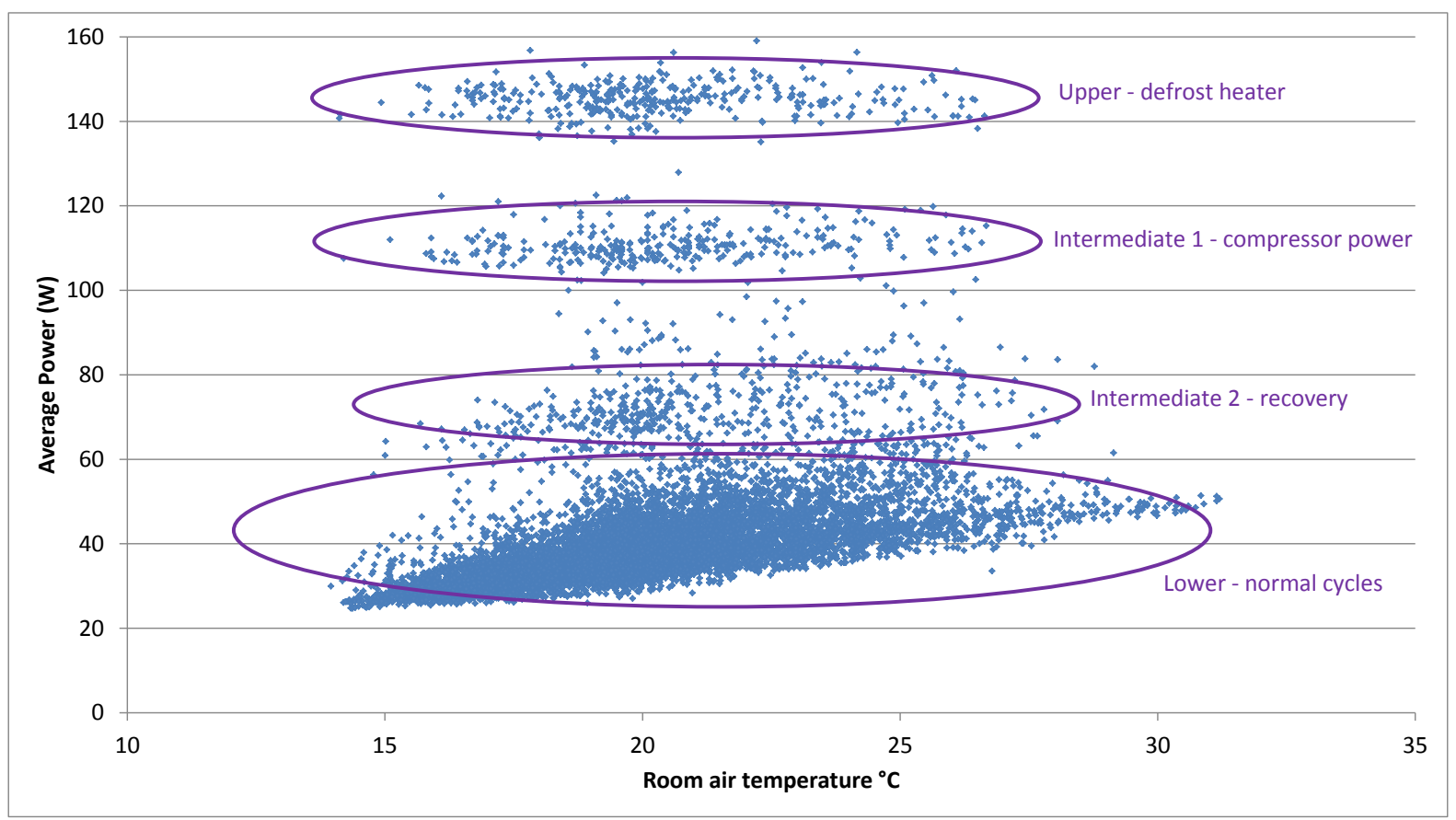

Fig. 2: Room air temperature versus average power per cycle for all cycles (Source: Field data collected and analysed by the authors, unit ID RFoo31, Gippsland, Victoria. Average power is calculated over each whole compressor cycle for a cycling unit.)

The lower cloud has a relatively sharp lower edge. It is thus possible to manually adjust a curve to just touch the bottom edge of the lower steady state cloud as an approximation of the steady state power of the appliance with no user interaction as a function of ambient temperature, shown as the Lower Boundary in Fig. 3.

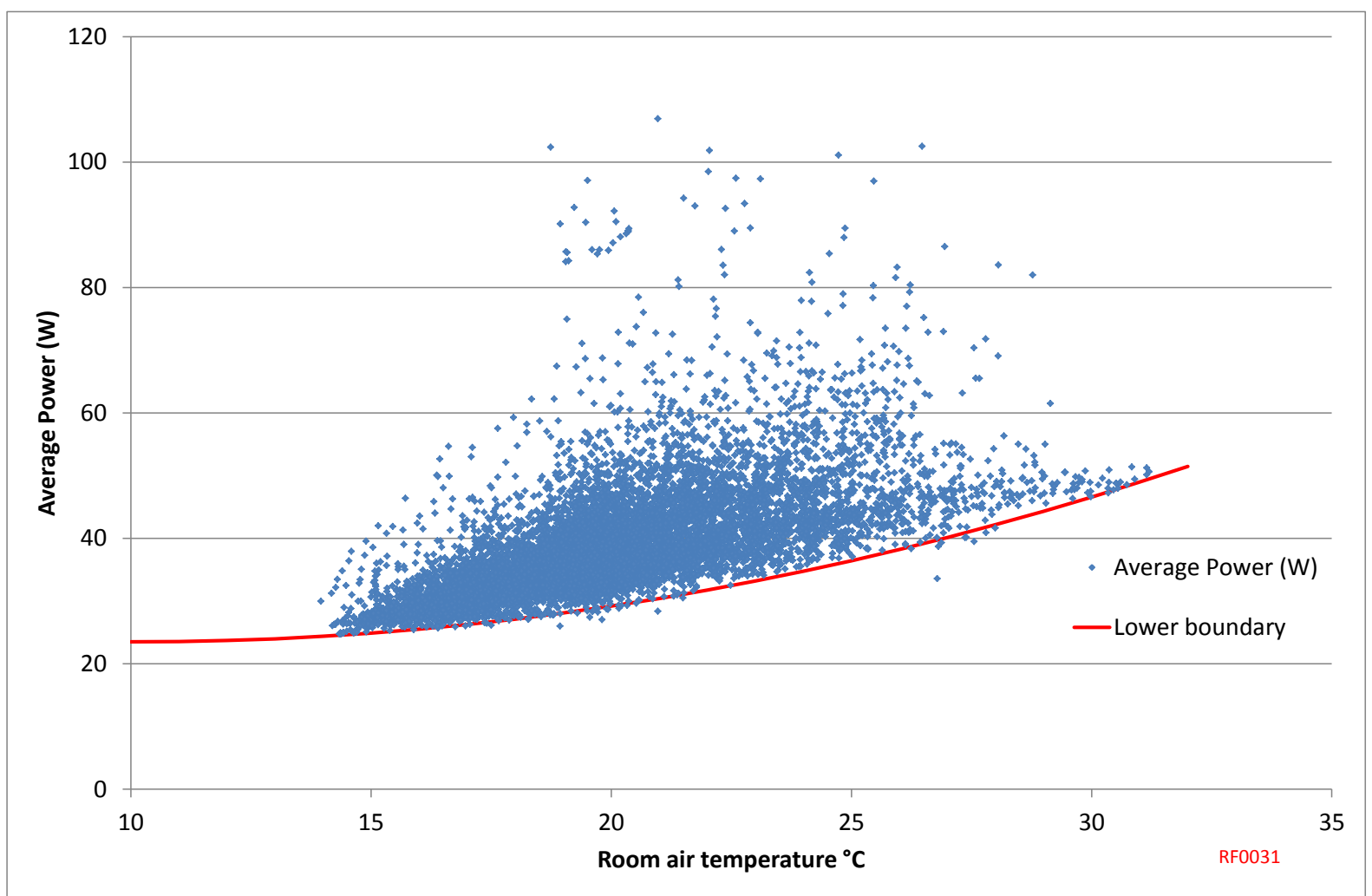

Fig. 3: Manual adjustment of a curve to the lower boundary of compressor cycle average power (excludes defrost and recovery) 
This critical step allows the underlying energy consumption of each appliance to be estimated quite accurately across a range of room air temperatures. Most data points lie well above the Lower Boundary. The difference between each data point and the Lower Boundary is the energy induced in the refrigerator by user interactions. This is examined in more detail in a later section.

The Lower Boundary of the steady state curve may not be distinct for a number of reasons. Firstly, products that use an ambient compensation heater that is automatically activated by ambient temperature or compressor run-time may appear to have variable average power consumption at a specific ambient temperature. It is possible to detect when such a heater is "on" or "off" by examining the power when the compressor is "off". This allows a more sophisticated analysis to be undertaken where two separate curves are generated: one when the heater is "on" and one when the heater is "off". If this were the case, Fig. 3 would have two Lower Boundary curves. These heaters will be "on" most of the time at low room air temperatures $\left(<20^{\circ} \mathrm{C}\right)$ and "off" most of the time for warmer room air temperatures. A similar effect would be caused by ambient controlled anti-condensation heaters, but these tend to be on more and operate at higher powers in higher room air temperatures.

Another factor that can make the Lower Boundary appear indistinct is where appliances have a sequence of long and short compressor cycles. This typically occurs in products with electronic controls where they can fully modulate the cooling into each compartment. For example, some products at low room air temperatures cool the freezer on every compressor cycle and the fresh food only on every second compressor cycle. This appears as a short compressor cycle (without fresh food cooling) followed by a long cycle (with fresh food and freezer cooling) with lower and higher power respectively than would be expected for an appliance that exhibited even length cycles at that temperature.

The Lower Boundary curve and individual compressor cycles in Fig. 3 are then replotted in sequence through the monitoring period with time on the $\mathrm{X}$ axis as shown in Fig. 4. This allows a closer examination of the data from day-to-day.

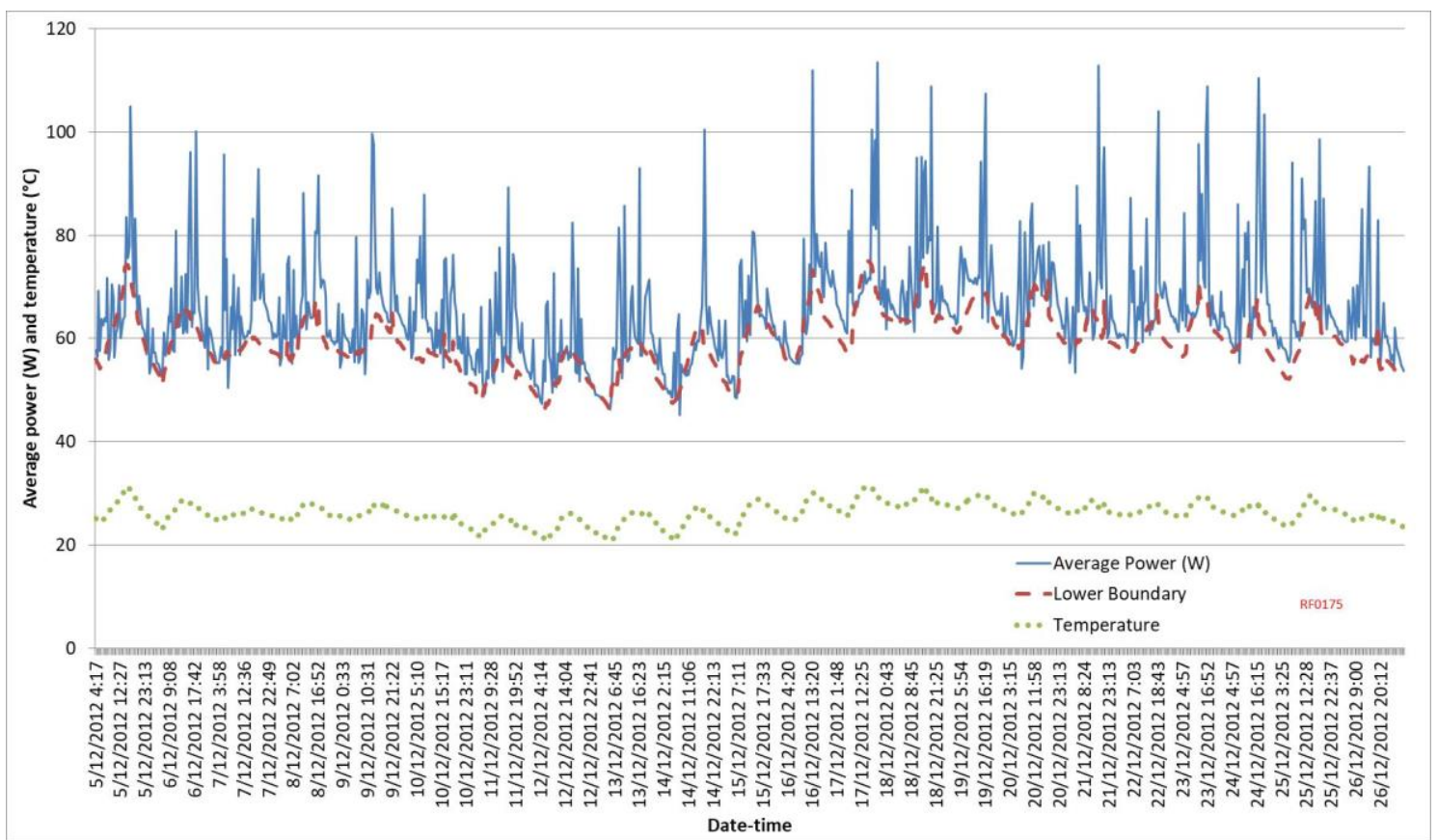

Fig. 4: Example of actual data versus modelled (no user interactions) data for a selected appliance over three weeks (Source: Field data collected and analysed by the authors, unit ID RFo175, Brisbane, Queensland. Note data in the figure excludes defrost and recovery events.) 
The solid line is the measured power consumption for each compressor cycle while the dashed line is the manually fitted Lower Boundary for the specific appliance, similar to that shown in Fig. 3. This dashed line, called Lower Boundary in the legend, represents likely average power of the appliance with no user interactions for a given room air temperature. The data shown excludes defrost and recovery events.

Conceptually, the solid line should never fall below the dashed line, as this represents the minimum power that the appliance is expected to use at the ambient temperature that was measured during each compressor cycle. The dashed line and solid line should coincide from time to time where the appliance fully recovers from user interactions and reverts back to steady state operation. This often occurs overnight, but some larger user loads (like a large load of newly purchased food and drink) can take up to 16 hours to fully cool, so on some days the solid line may always lie above the dashed line for extended periods, particularly in warmer months.

If the Lower Boundary curve is correct, the dashed line should nestle into the shape of the solid line over a period of days or weeks. If there are extended periods where the solid line falls below the dashed line or where there is a significant ongoing gap where the solid line sits well above the dashed line, then this suggests that the user may have changed the temperature control setting in the appliance. In this analysis the Lower Boundary curve was adjusted up or down by a few watts to compensate for different user control settings throughout the monitoring period. This adjustment was usually small and an estimate of the impact is somewhat visual in nature. This process effectively creates a family of lower boundaries, one for each control setting that applies to a specific subset of the monitoring period. The Lower Boundary for the appliance (dashed line) is required so that energy associated with user interactions can be separated from temperature driven energy consumption.

It is evident from Fig. 4 that the Lower Boundary for a given room air temperature will explain the majority of the energy consumption of the appliance. This average power characteristic is dictated by the appliance design and construction and is driven by room air temperature.

\subsection{Defrost and recovery energy}

Many years of experience with the new IEC standard, including intensive development work for the IEC and the Australasian round robin of refrigerating appliances to the new IEC test method in 2014 that covered two appliances in six laboratories (Harrington 2015), has enabled the defrosting behaviour of appliances to be well understood and characterised using just a handful of key parameters. In a laboratory setting, with no user interaction, the IEC test method calculates the additional energy associated with a defrost and recovery event with great accuracy (IEC62552-3 2015).

The overall approach is to measure the energy consumed during defrost and recovery (including steady state power on either side of the defrost heater) and to estimate the additional energy of the defrost event after deducting the steady state power (energy) that would have occurred during the period when the defrost and recovery occurred. In general terms, the incremental defrost and recovery energy (known as $\Delta E_{d f}$ ) is a very stable value in the laboratory setting (stable temperature, no user interaction). Extensive investigations on more than 100 appliances and many thousands of defrosts in the laboratory have shown that this value is largely unaffected by room air temperature or control setting, so is effectively a key appliance characteristic. Analysis during the Australasian round robin has revealed that the additional energy associated with defrost and recovery can be approximated as the defrost heater energy plus a "fixed energy defrost adder" (in Wh). The fixed energy defrost adder will vary by model and can also be considered as a characteristic of the appliance.

Detailed analysis has shown that most of the energy associated with a defrost and recovery event is relatively fixed as the energy associated with melting of frost, the heating of the evaporator metal and the refrigerant (all heater energy) and the subsequent cooling of the 
evaporator, the heater element and refrigerant (additional compressor energy) does not change much with room air temperature or control setting (Harrington et al. 2018a). However, using field data presents many problems, because typically there is processing of heat loads from user interactions and the ambient temperature is constantly changing. These effects are usually mixed into most defrost and recovery events, making an analysis of defrost energy based on the IEC approach impossible. However, the energy associated with the defrost heater alone can be accurately measured in the field and this provides a key piece of data. The approach used for this project involves the following steps for each defrost and recovery event:

1. identify the defrost heater operation and determine the defrost heater energy consumption.

2. add the total measured energy associated with the compressor cycle before the defrost heater (pre-cool), the defrost heater operation and the compressor cycle after the defrost heater (recovery cycle).

3. subtract the expected steady state power that the appliance would have used at the room air temperature during the defrost and recovery (Lower Boundary power) times the length of the three associated cycles (pre-cool, defrost heater, recovery) to give total net energy for the defrost and recovery event.

4. subtract the defrost heater energy to give net residual energy in Wh for the defrost and recovery event.

5. perform these calculations for all available defrost and recovery events.

6. review the net residual energy for each defrost and recovery event to determine a typical minimum value for all defrost and recovery events.

7. subtract the typical minimum value for net residual energy from all defrost and recovery events.

8. all remaining energy for each defrost and recovery event is then allocated to userrelated processing load during that period.

When the net residual energy is plotted for each defrost (Step 6), it usually becomes clear that there is a minimum value that regularly occurs for the appliance - an example is shown in Fig. 5. In this example it is evident that the minimum value is about $40 \mathrm{Wh}$ for this particular appliance. This minimum value represents defrost and recovery events that had little or no user load processing present. The observed minimum energy for net residual energy is an estimate of the fixed energy defrost adder for the appliance, which is effectively the additional cooling energy to return the evaporator, refrigerant and other components back to their operating temperature when there is no user processing load (Harrington et al. 2018a). The fixed energy defrost adder plus the defrost heater energy is a good estimate of the additional energy associated with defrost and recovery for each defrost - this value is fairly comparable to the IEC value for $\Delta E_{d f}$.

Review of the data analysed for this paper reveals that the average energy for a defrost heater is around $95 \mathrm{Wh}$ (this depends on the evaporator size) with the smallest average value measured at $50 \mathrm{Wh}$ and the largest average value at $150 \mathrm{Wh}$. Most appliances have a fixed energy defrost adder value in the range $15 \mathrm{Wh}$ to $60 \mathrm{Wh}$ on top of the defrost heater energy older and poorly performing appliances can be as high as $100 \mathrm{Wh}$, although values of more than $50 \mathrm{Wh}$ are not very common. Appliances with only unfrozen compartments tend to have a fixed energy defrost adder close to zero where an active defrost and recovery cycle is present. This means a typical incremental defrost and recovery energy $\Delta E_{d f}$ for refrigerator-freezers measured in this study is $130 \mathrm{Wh}$ (range from $70 \mathrm{Wh}$ to $240 \mathrm{Wh}$ ). A detailed comparison of defrosting energy in the laboratory and in the field is given in Harrington et al. (2018a).

This approach allows the additional energy associated with each defrost to be approximated from field data for each appliance. The incremental defrost and recovery energy is an 
important parameter that is characteristic of each refrigerator. While the incremental defrost and recovery energy for each defrost is fairly constant, the variation in total defrost energy during use is largely determined by frequency of defrosting. As room air temperatures and user interactions increase, the defrost interval will shorten. An example of variations in defrost interval over a year is illustrated in Fig. 6.

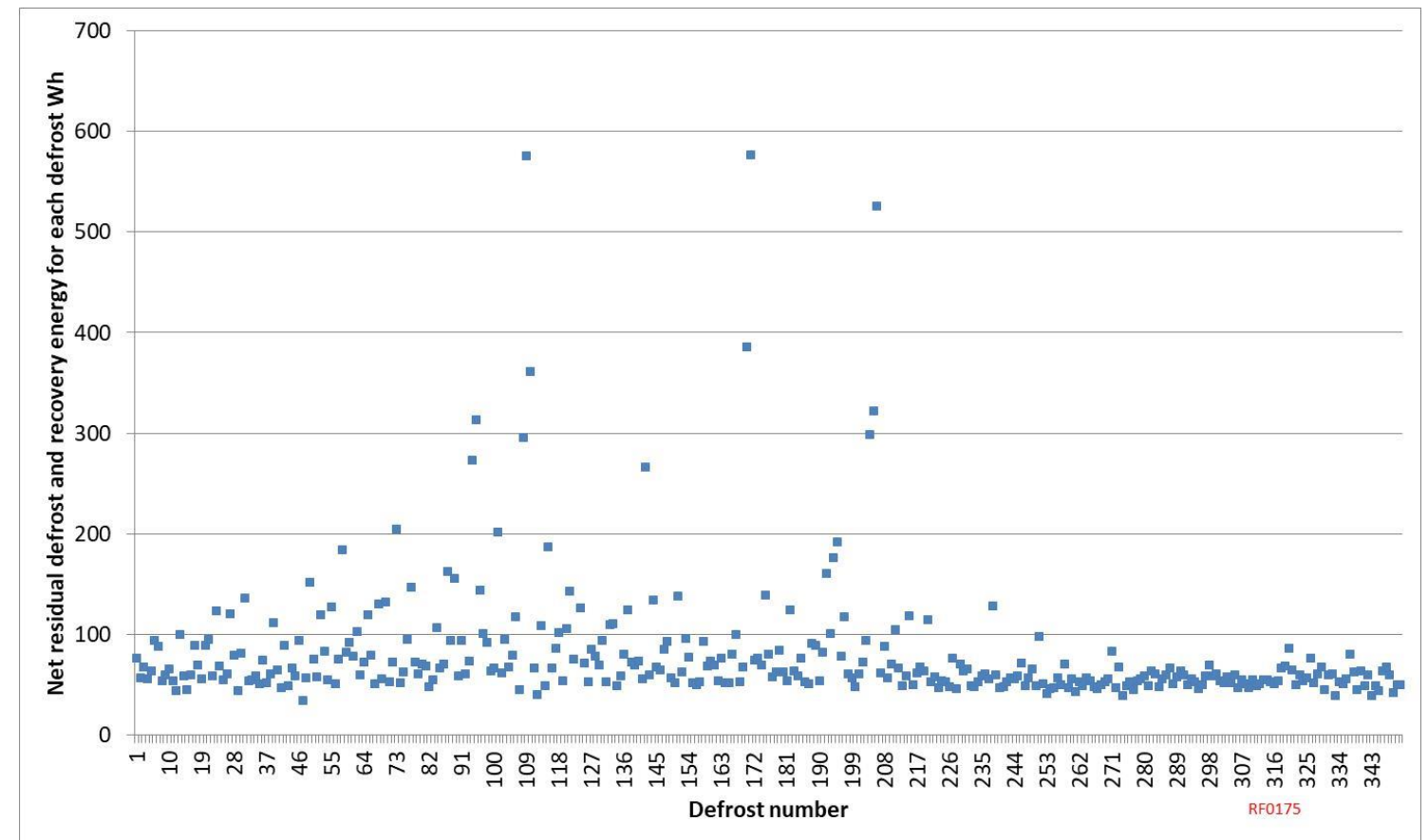

Fig. 5: Net residual energy for all defrost and recovery events for a measured appliance over nine months (Source: Field data collected and analysed by the authors, unit ID RFo175, Brisbane, Queensland.)

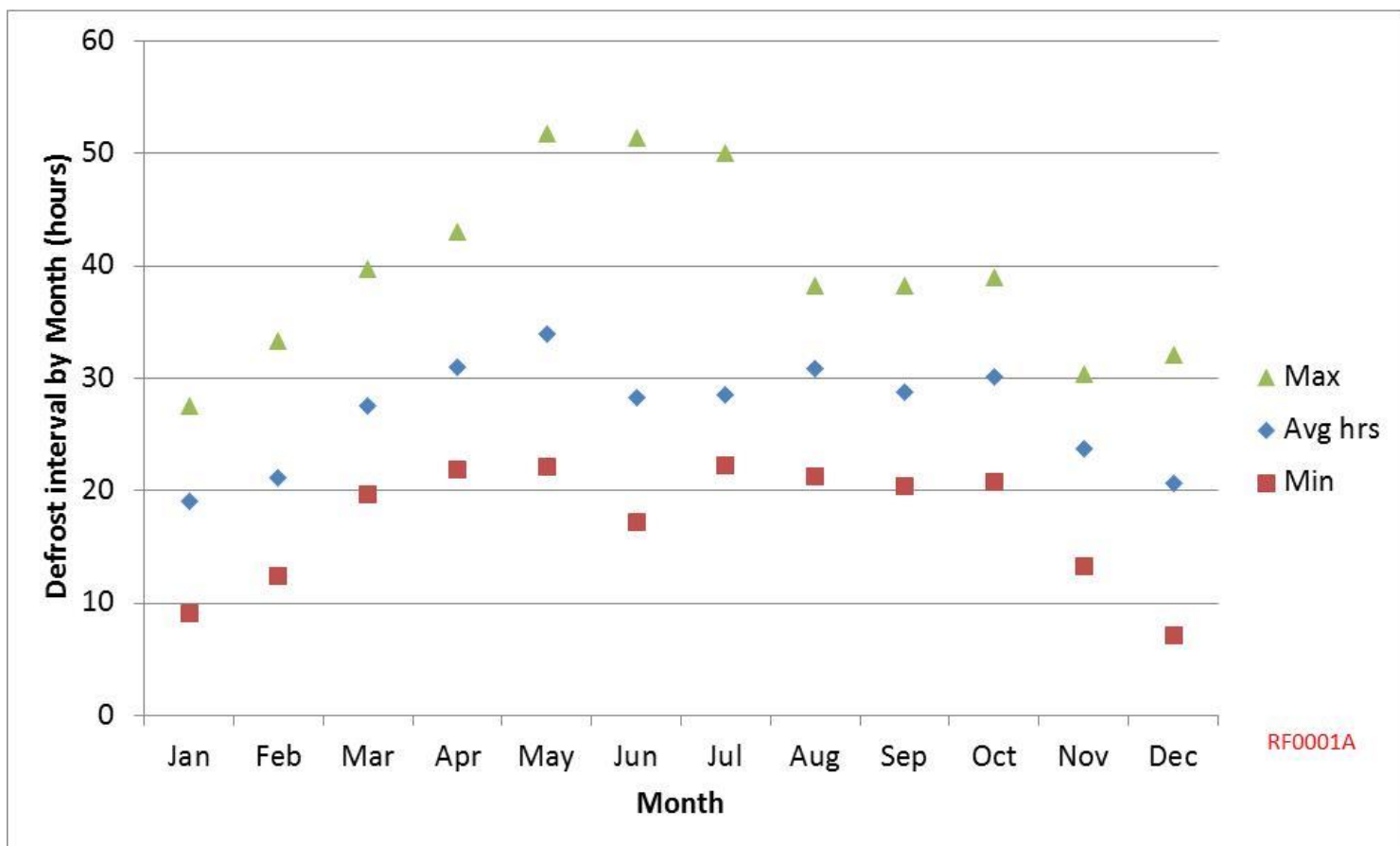

Fig. 6: Example of defrost intervals by month over a year for a variable defrost controller (Source: Field data collected and analysed by the authors, unit ID RFoooıA, Gippsland, Victoria.) 


\subsection{User interactions}

User-driven energy consumption has two separate components. The first and most obvious user impact is from interactions such as door openings and the insertion of food and drinks. Additional humidity from ambient air ingress during door openings and also from respiration of fruit and vegetables, as well as uncovered liquids, increases the water vapour in the compartment air. This presents as a latent heat load, as water vapour is condensed and sometimes turns into frost on the evaporator. Sensible and latent heat loads require the appliance to undertake additional cooling over and above steady state conditions that result from heat gain alone.

The second element of user-driven energy consumption is defrosting. When there is no user interaction with the appliance, it will defrost from time to time in any case. This defines the base defrosting energy. With heavier use or during warmer temperatures, the appliance will defrost more frequently. The total defrosting energy observed can then be split into base defrosting energy and user-driven defrosting energy, which is the total defrost energy minus the base energy. Base and user defrost energy have not been separately quantified in this paper. There is often some time delay between when user interactions occur and the occurrence of the next defrost.

The total user-driven energy consumption is calculated for each compressor cycle as the difference between measured energy consumption and the estimated steady state power of the appliance at the given ambient temperature (Lower Boundary) as discussed in the previous section. It is important to remember that this approach only allocates a share of total energy to each component - the total energy consumption will always be as measured.

Investigation of laboratory research data suggests that even moderately sized loads in the refrigerator (say a few litres of warm water) could require as long as 6 to 10 hours to reach the compartment temperature (Sustainability Victoria 2017; Harrington 2015). Therefore, it is not surprising that some apparent residential user load was present in the field data in the early hours of the morning on many days.

The method set out in this paper quantifies the additional energy induced by user interactions for a particular appliance in a particular household over a particular period. User loads make up a significant additional component of heat load that the refrigeration system has to remove during normal use. However, the user load estimated using this approach is an estimate of the additional energy induced in the specific appliance by the specific user sensible and latent heat loads encountered during the measurement period, rather than an estimate of the sensible and latent heat loads themselves. Sensible and latent heat loads are of interest because they can be related back to climate, room air temperature, appliance size and number of householders. In order to estimate sensible and latent heat loads in a house, it is necessary to have some means of estimating the refrigeration system COP, which is a measure of how efficiently internal heat is extracted. This parameter is defined as an IEC test in IEC62552-3 Annex $\mathrm{G}$ and is called the load processing efficiency. However, this adds considerable complexity to the analysis. An assessment of the relative COP of each appliance has not been made for this paper, but is an area where further research is warranted.

\section{$4 \quad$ Results and discussion}

The data collected for 235 refrigerating appliances has been processed using the method described in the previous section. This section discusses the results of this analysis.

\subsection{Share of energy by component}

The total daily energy consumption, split into temperature-driven energy, defrost energy and user-induced energy, is illustrated in Fig. 7. There are some qualifications that must be made regarding this data. The data was collected over a period of about four years in different cities, so it is not possible to directly compare appliances over a common period. However, detailed information on indoor and outdoor temperature was collected, so this provides sufficient data 
for a deeper investigation. Household sizes also varied from one to as many as 10 people in a few cases. The length of monitoring varies from as little as six weeks to over one year, so the daily average value will be impacted to some extent by the time of year and length of monitoring. Most sites were monitored for a period that covered winter and summer and this data showed, as expected, the total energy consumption of refrigerators and freezers is somewhat seasonal. The data also spans climates from Cairns in northern Australia to Melbourne and Gippsland in the south. Fig. 8 illustrates the measured average room air temperature adjacent to each refrigerator during the monitoring period to provide some relative indicator of the influence of room air temperature on energy consumption.

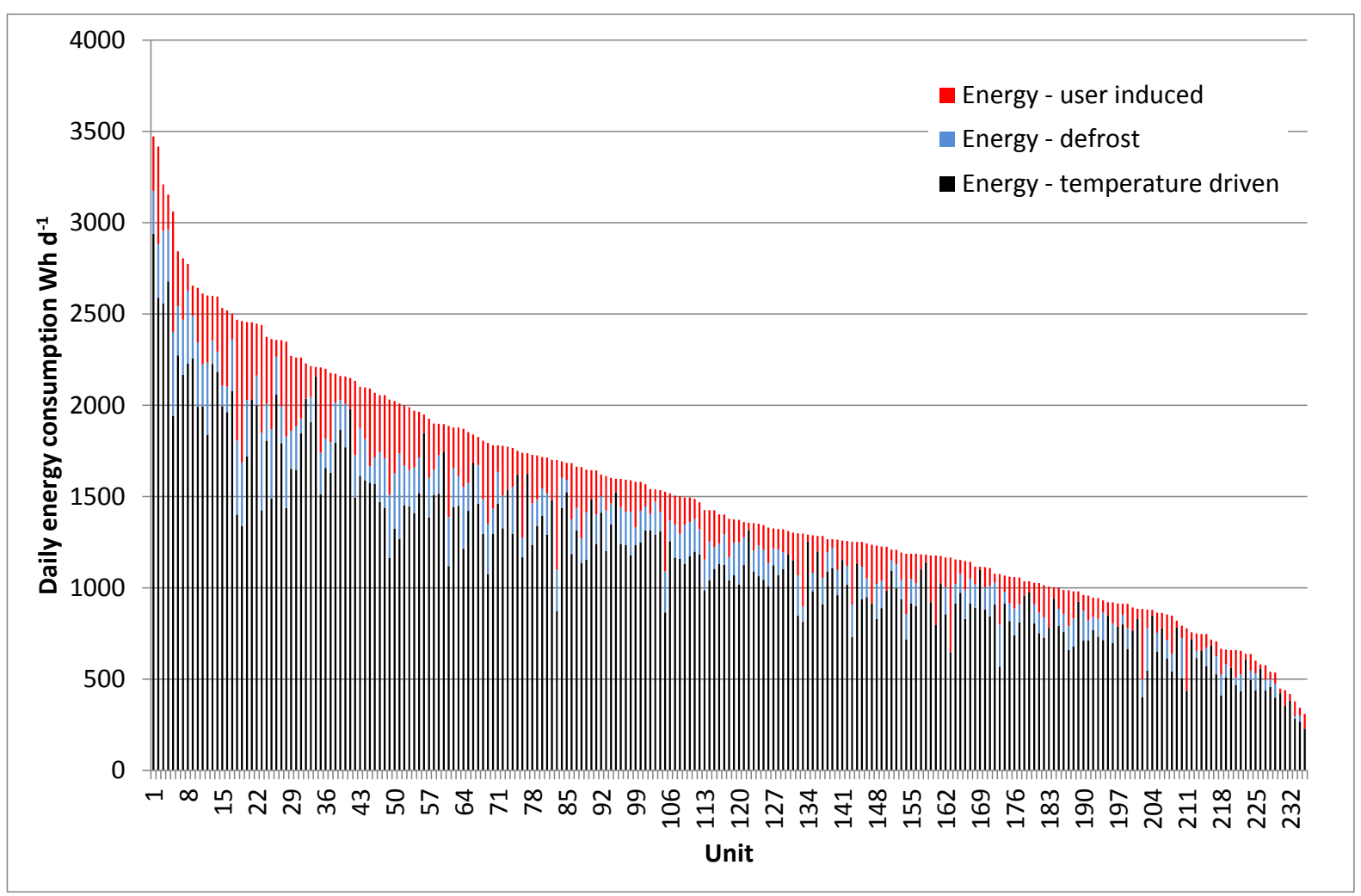

Fig. 7: Average daily energy consumption 235 appliances disaggregated into components (Source: Field data collected and analysed by the authors. Units sorted by total measured daily energy.)

There are several interesting observations that can be made from Fig. 7 and Fig. 8. The first and most striking feature is that the ratio of the lowest to the highest energy consumption is a factor of 10, which is quite remarkable. The shape of this distribution is very similar to the data collected in Sweden for 400 households in 2008 (Zimmermann 2009) and for 405 refrigerators and freezers in the UK (Zimmermann et al. 2012). The difference in energy consumption will, to some extent, be influenced by climate, season and room air temperature. However, the data in Fig. 8, when examined in conjunction with Fig. 7, shows that the difference in average room air temperature during monitoring for these houses, while significant, only explains part of the variation in energy. The majority of the difference in energy between houses appears to be due to the energy consumption characteristics of each refrigerator, which is determined by the product design and construction. This is unsurprising as typically more than $75 \%$ of the total energy consumption can be explained by room air temperature alone. To illustrate the importance of the underlying energy performance of each refrigerator, the average power consumption for all units at a room air temperature of $22{ }^{\circ} \mathrm{C}$ is shown in Fig. 9. This is based on the temperature-power curve (Lower Boundary) developed for each appliance from field data and excludes defrosting and usage. This data also shows a ratio of about 10 from lowest to 
highest energy, although the ranking is slightly different as the climate and usage varies for each appliance. Further analysis of the data revealed that the share of energy by component is as set out in Table 1.

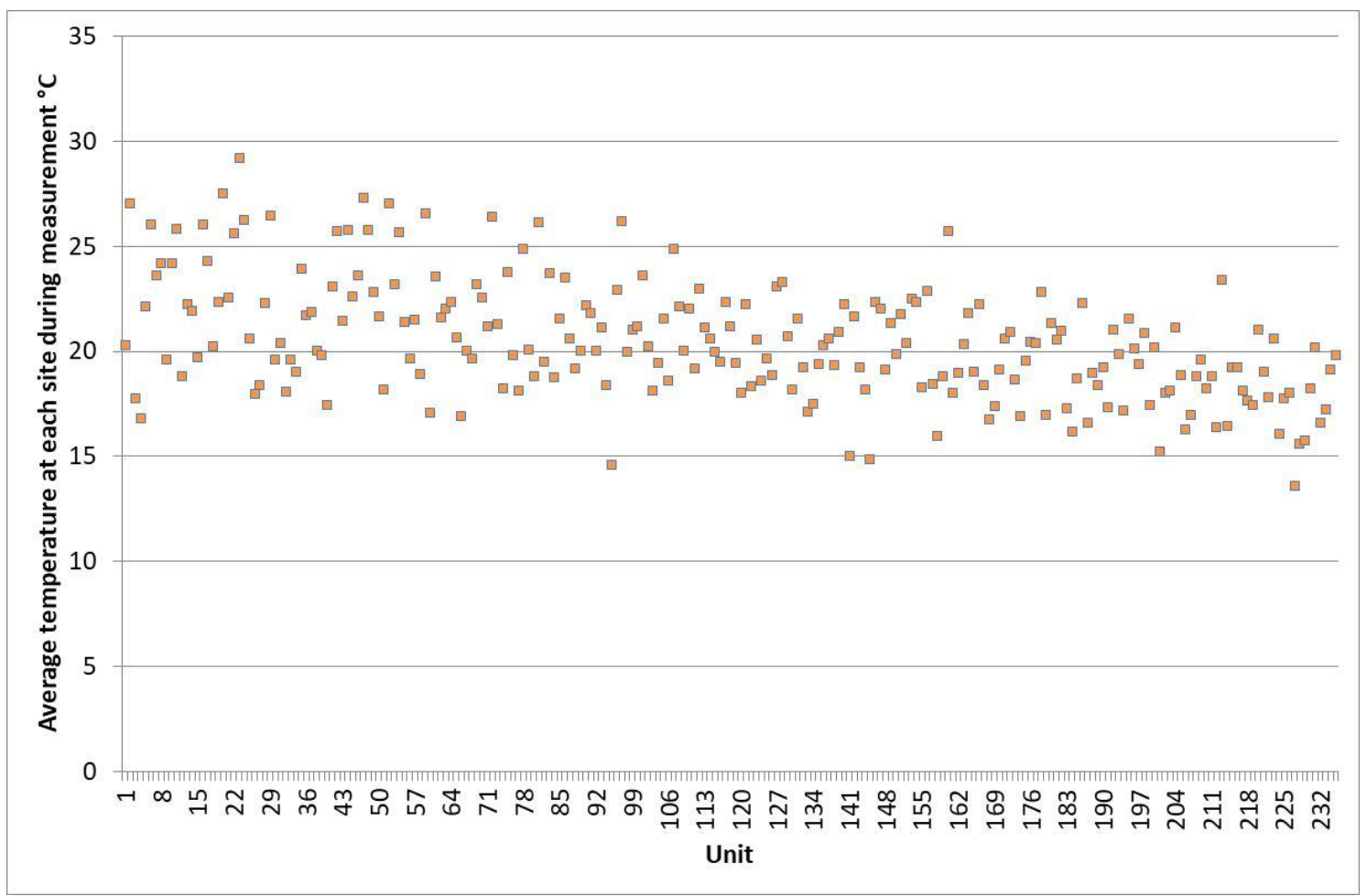

Fig. 8: Average room air temperature at each site during the monitoring period for 235 appliances (Source: Field data collected and analysed by the authors. Same unit numbering as Fig. 7.)

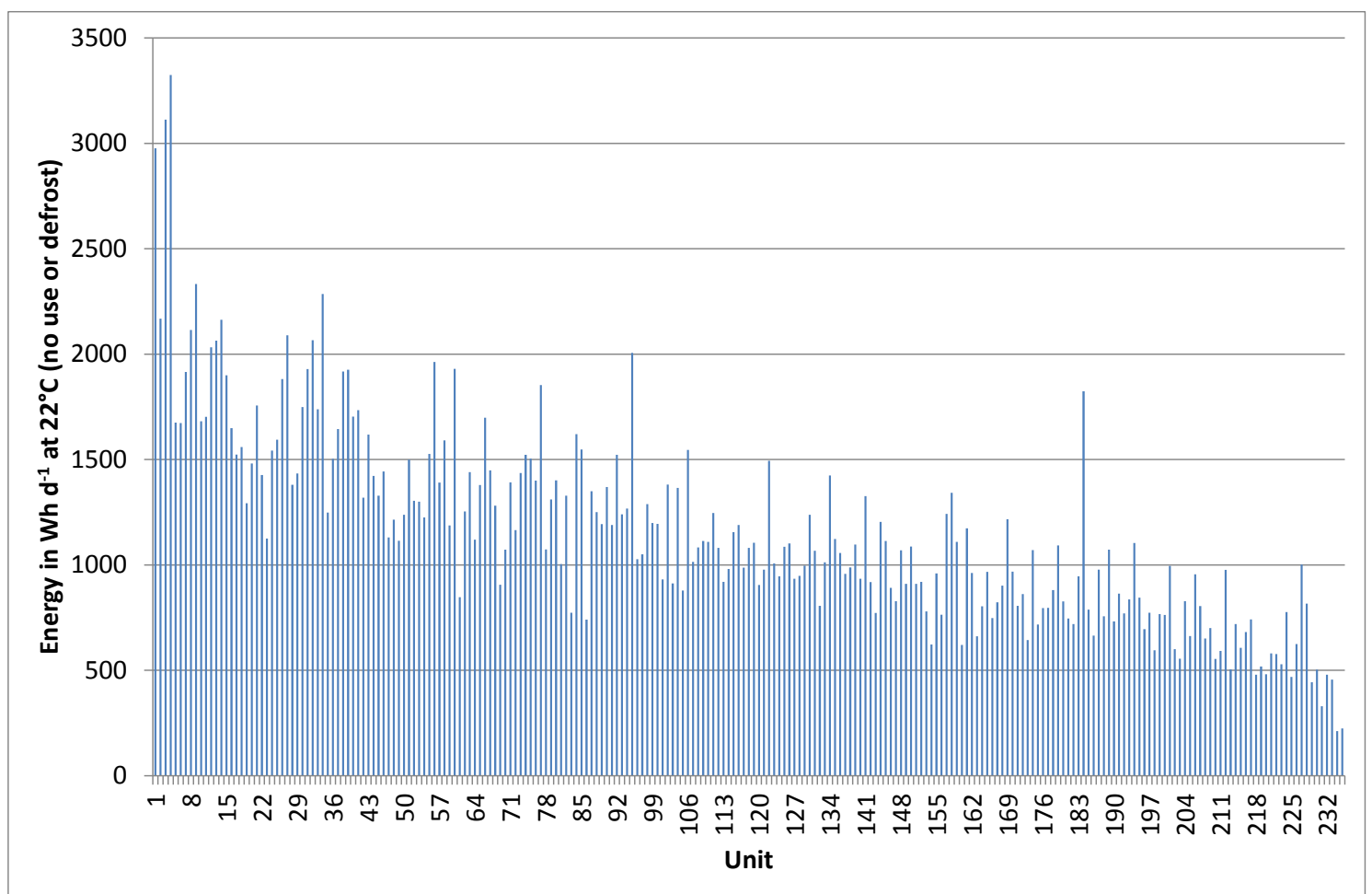

Fig. 9: Estimate average steady state power at $22{ }^{\circ} \mathrm{C}$ for 235 appliances (Source: Field data collected and analysed by the authors. Same unit numbering as Fig. 7.) 
Table 1:

Share of daily energy consumption disaggregated into components for 235 appliances by climate

\begin{tabular}{|c|c|c|c|c|c|c|c|}
\hline Region & $\begin{array}{r}\text { Temperature } \\
\text { related } \\
\%(\mathrm{SD})\end{array}$ & $\begin{array}{l}\text { Defrost } \\
\text { related } \\
\%(\mathrm{SD})\end{array}$ & $\begin{array}{r}\text { User } \\
\text { related } \\
\%(\mathrm{SD})\end{array}$ & $\begin{array}{r}\text { Total E } \\
\text { Wh d }^{-1} \\
(\mathrm{SD})\end{array}$ & $\begin{array}{r}\text { Defrost } \\
\text { Interval } \\
\mathrm{h}(\mathrm{SD})\end{array}$ & $\begin{array}{r}\text { Room } \\
\text { Temperature } \\
{ }^{\circ} \mathrm{C} \text { (SD) }\end{array}$ & Count \\
\hline Gippsland ADF & $\begin{array}{r}75.9 \\
(8.0) \\
\end{array}$ & $\begin{array}{r}10.6 \\
(4.0) \\
\end{array}$ & $\begin{array}{r}13.5 \\
(7.4) \\
\end{array}$ & $\begin{array}{r}1355 \\
(436) \\
\end{array}$ & $\begin{array}{r}24.2 \\
(8.9) \\
\end{array}$ & $\begin{array}{l}19.1 \\
(1.1) \\
\end{array}$ & 40 \\
\hline Melbourne ADF & $\begin{array}{r}75.4 \\
(6.6)\end{array}$ & $\begin{array}{r}11.7 \\
(3.8)\end{array}$ & $\begin{array}{r}12.9 \\
(5.3)\end{array}$ & $\begin{array}{r}1297 \\
(733)\end{array}$ & $\begin{array}{r}24.8 \\
(10.7)\end{array}$ & $\begin{array}{l}18.4 \\
(2.1)\end{array}$ & 35 \\
\hline Sydney ADF & $\begin{array}{l}76.7 \\
(7.3) \\
\end{array}$ & $\begin{array}{r}10.4 \\
(3.6) \\
\end{array}$ & $\begin{array}{r}13.0 \\
(4.9) \\
\end{array}$ & $\begin{array}{r}1562 \\
(531) \\
\end{array}$ & $\begin{array}{r}23.7 \\
(8.9) \\
\end{array}$ & $\begin{array}{l}20.9 \\
(1.2) \\
\end{array}$ & 38 \\
\hline Brisbane * ADF & $\begin{array}{r}71.8 \\
(10.0) \\
\end{array}$ & $\begin{array}{r}11.1 \\
(3.6) \\
\end{array}$ & $\begin{array}{r}17.1 \\
(7.7) \\
\end{array}$ & $\begin{array}{r}1773 \\
(529) \\
\end{array}$ & $\begin{array}{r}19.7 \\
(7.2) \\
\end{array}$ & $\begin{array}{r}22.6 \\
(0.9) \\
\end{array}$ & 33 \\
\hline Cairns ADF & $\begin{array}{r}74.1 \\
(5.0) \\
\end{array}$ & $\begin{array}{r}10.9 \\
(2.6) \\
\end{array}$ & $\begin{array}{r}14.9 \\
(3.5) \\
\end{array}$ & $\begin{array}{r}2186 \\
(453) \\
\end{array}$ & $\begin{array}{r}15.7 \\
(3.7) \\
\end{array}$ & $\begin{array}{l}26.3 \\
(1.0) \\
\end{array}$ & 21 \\
\hline Average main ADF & $\begin{array}{r}74.7 \\
(7.9) \\
\end{array}$ & $\begin{array}{r}11.0 \\
(3.9) \\
\end{array}$ & $\begin{array}{r}14.2 \\
(6.3) \\
\end{array}$ & $\begin{array}{r}1571 \\
(622) \\
\end{array}$ & $\begin{array}{r}22.2 \\
(9.0) \\
\end{array}$ & $\begin{array}{r}20.9 \\
(2.8) \\
\end{array}$ & 169 \\
\hline Average main NDF & $\begin{array}{r}83.0 \\
(11.2) \\
\end{array}$ & 0.0 & $\begin{array}{r}17.0 \\
(11.2) \\
\end{array}$ & $\begin{array}{r}1335 \\
(572) \\
\end{array}$ & $\# \mathrm{~N} / \mathrm{A}$ & $\begin{array}{r}19.9 \\
(2.4) \\
\end{array}$ & 24 \\
\hline Secondary SDF & $\begin{array}{l}82.2 \\
(3.7) \\
\end{array}$ & $\begin{array}{r}9.8 \\
(2.8) \\
\end{array}$ & $\begin{array}{r}8.0 \\
(1.9) \\
\end{array}$ & $\begin{array}{r}2209 \\
(725) \\
\end{array}$ & $\begin{array}{r}18.0 \\
(5.0)\end{array}$ & $\begin{array}{l}20.6 \\
(2.5) \\
\end{array}$ & 7 \\
\hline Freezers NDF & $\begin{array}{r}93.5 \\
(0.5) \\
\end{array}$ & 0.0 & $6.5(0.5)$ & $\begin{array}{r}1084 \\
(77) \\
\end{array}$ & \#N/A & $\begin{array}{r}18.3 \\
(0.4) \\
\end{array}$ & 28 \\
\hline Freezers SDF & $\begin{array}{r}79.0 \\
(2.2) \\
\end{array}$ & $\begin{array}{r}11.4 \\
(0.8) \\
\end{array}$ & $\begin{array}{r}9.6 \\
(1.5) \\
\end{array}$ & $\begin{array}{l}1647 \\
(214) \\
\end{array}$ & $\begin{array}{r}17.5 \\
(1.6) \\
\end{array}$ & $\begin{array}{r}20.5 \\
(0.6) \\
\end{array}$ & 7 \\
\hline \multicolumn{8}{|c|}{$\begin{array}{l}\text { Notes: SD is sample standard deviation and is shown in brackets in the same units. ADF is a main } \\
\text { refrigerator with automatic defrost. MDF is manual or no defrost. SDF is a secondary refrigerator or } \\
\text { separate freezer with automatic defrost. Appliances with ADF listed by region all have automatic defrost; } \\
\text { appliances MDF and SDF are from all regions (but predominantly from Victoria). Two appliances } \\
\text { included in the Average all ADF total were from other regions so are not in the regional totals. Brisbane * } \\
\text { includes Brisbane, Gold Coast and Byron Bay sub-regions. Indoor temperature is the measured average } \\
\text { for the periods metered for each appliance. Two appliances in Average main NDF are secondary } \\
\text { appliances. Freezers are often located in unconditioned parts of the house so tend to have lower room air } \\
\text { temperatures. Freezers NDF is made up of } 15 \text { vertical freezers and } 13 \text { chest freezers. }\end{array}$} \\
\hline
\end{tabular}

\subsection{Discussion}

The temperature-driven component of energy is determined by the room air temperature in which the appliance operates. However, when assessing the data, it is conceptually more useful to think of this as a larger fixed energy component and a smaller variable energy component that is influenced by room air temperature. For example, the energy consumption of a refrigerator-freezer or a separate freezer at a room air temperature of $16^{\circ} \mathrm{C}$ is about half the energy consumption at a room air temperature of $32{ }^{\circ} \mathrm{C}$, so room air temperature is a very important determinant of the expected energy consumption in the home. But the slope of the power curve at around $20{ }^{\circ} \mathrm{C}$ is typically about $5 \%$ per degree (Harrington et al. 2018b), so across the range of normal indoor room air temperatures in a specific home, which is likely to be with $\pm 2 \mathrm{~K}$ during any particular month (Harrington et al. 2015), the energy does not vary all that much (around $\pm 10 \%$ ).

The most interesting observation from Table 1 is that the share of temperature-driven energy and defrosting energy remains fairly constant across climates. This is likely to be because the share of energy for each component scales in a linear fashion with temperature. The data also shows, somewhat surprisingly, that the share of user-related energy is fairly constant for a wide range of climates, although there does appear to be a very small increase in user share for hotter climates. Note that these are average data across all available sites and user load does vary considerably by household, as is illustrated by the higher standard deviation for the user-related energy as set out in Table 1 . A more detailed investigation into the factors that affect the magnitude of user interactions has been undertaken and is being 
prepared for publication. As expected, the defrost interval by climate becomes shorter for hotter climates. The sample from Melbourne was disproportionately measured for periods that covered the cooler winter months, so this explains why the energy and average room air temperature is slightly lower than might be expected for this climate.

The energy consumption of single door appliances (predominantly those that had only a fresh food storage compartment) was examined. This showed that the user-induced energy consumption was significantly higher at $23.3 \%$ of energy consumption (compared to $14.2 \%$ of refrigerator-freezers with automatic defrost). However, the user-induced energy (in $\mathrm{Wh} \mathrm{d}^{-1}$ ) was in fact lower than a refrigerator-freezer because the total energy was also significantly lower for single door appliances. Analysis shows that single door appliances have a much stronger response to changes in ambient temperature (Harrington et al. 2018b) and at normal operating temperatures, their energy consumption will be significantly lower relative to the Australian labelling test condition (AS/NZS4474.1 2007).

All three components of energy consumption appeared to show seasonal variation. To illustrate this aspect, data for all appliances was averaged by month as illustrated in Fig. 10. This clearly shows the relative contribution of each component to total energy consumption.

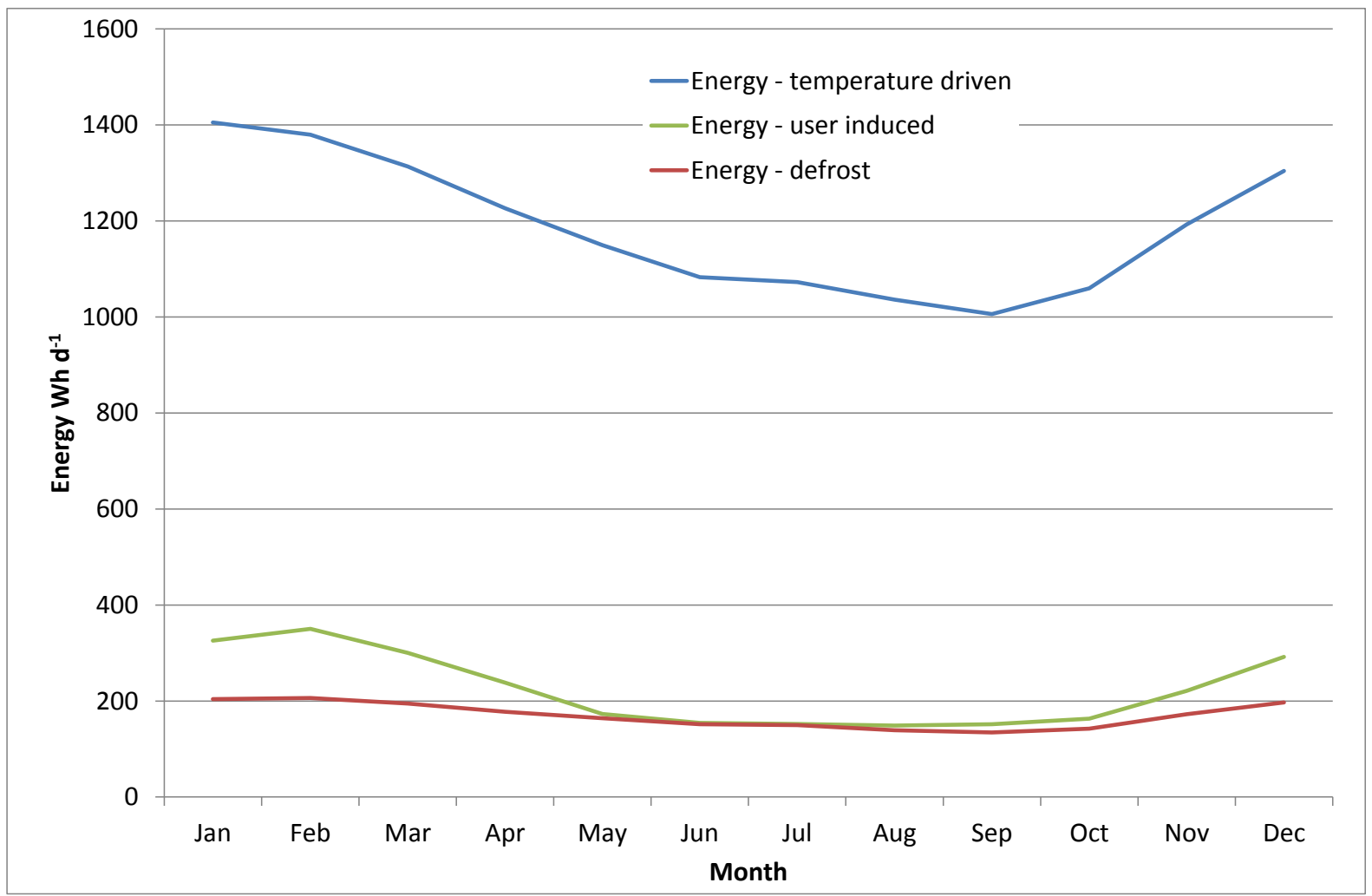

Fig. 10: Average seasonal variation for each energy component for 235 appliances (covers all appliances and all periods, note that summer is December to February, Source: Field data collected and analysed by the authors)

While this data is necessarily fairly general as it covers all appliance types, product sizes, family sizes and climates, it does illustrate that the temperature-driven component increases by about $40 \%$ in summer compared to winter. While modest, defrost energy is also seasonal and increases to be about $53 \%$ more in summer compared to winter. The strongest seasonal component is user-induced energy which increases by more than $135 \%$ in summer compared to winter. This suggests that user interactions are changing significantly with the seasons as the change is more than can be attributed to just room air temperature alone. It also shows that energy during normal use is dominated by the temperature-driven component. While the temperature-driven component appears to dominate total energy 
consumption on average, there are some examples in the sample where user-induced energy can be very high (as much as $45 \%$ in some cases). The energy response to temperature is determined by the appliance design and construction (insulation levels, compressor performance, heaters and auxiliaries), which is the aspect that is predominantly assessed under test procedures such as the Australian and previous international test methods (AS/NZS4474.1 2007; IEC62552 2007). However, these historical test procedures tend to assess energy consumption at a single temperature, which tends to be elevated to compensate for user interactions (Grimes et al. 1977; Koa and Kelly 1996; Market Transformation Programme 2007). However, detailed analysis of the typical response in energy consumption to changes in room air temperature shows that the relative response does vary somewhat by product configuration, with products with only fresh food having the largest response and products that only have a freezer having the lowest response (Harrington et al. 2018b). This is where the new IEC test procedure for energy consumption of refrigerating appliances (IEC62552-3 2015) has a great advantage, as the energy is measured at two ambient temperatures and this allows the likely energy consumption at any intermediate operating temperature to be estimated with some accuracy (Harrington et al. 2018b). It is possible to reorganise the data in Fig. 10 to show the impact of room air temperature on each of the main energy components, as illustrated in Fig. 11. In terms of the total change in energy with temperature, the temperature driven component is the largest at around $55 \mathrm{Wh} \mathrm{d}^{-1} \mathrm{~K}^{-1}$, while user-induced energy is next largest is user-induced energy at $31 \mathrm{Wh} \mathrm{d}^{-1} \mathrm{~K}^{-1}$, with defrost energy having the smallest response at $10 \mathrm{Wh} \mathrm{d}^{-1} \mathrm{~K}^{-1}$. This illustrates that an artificial change in test temperature alone with no user interaction is not likely to accurately account for the changes in other parameters such as user-induced energy and defrosting during normal use.

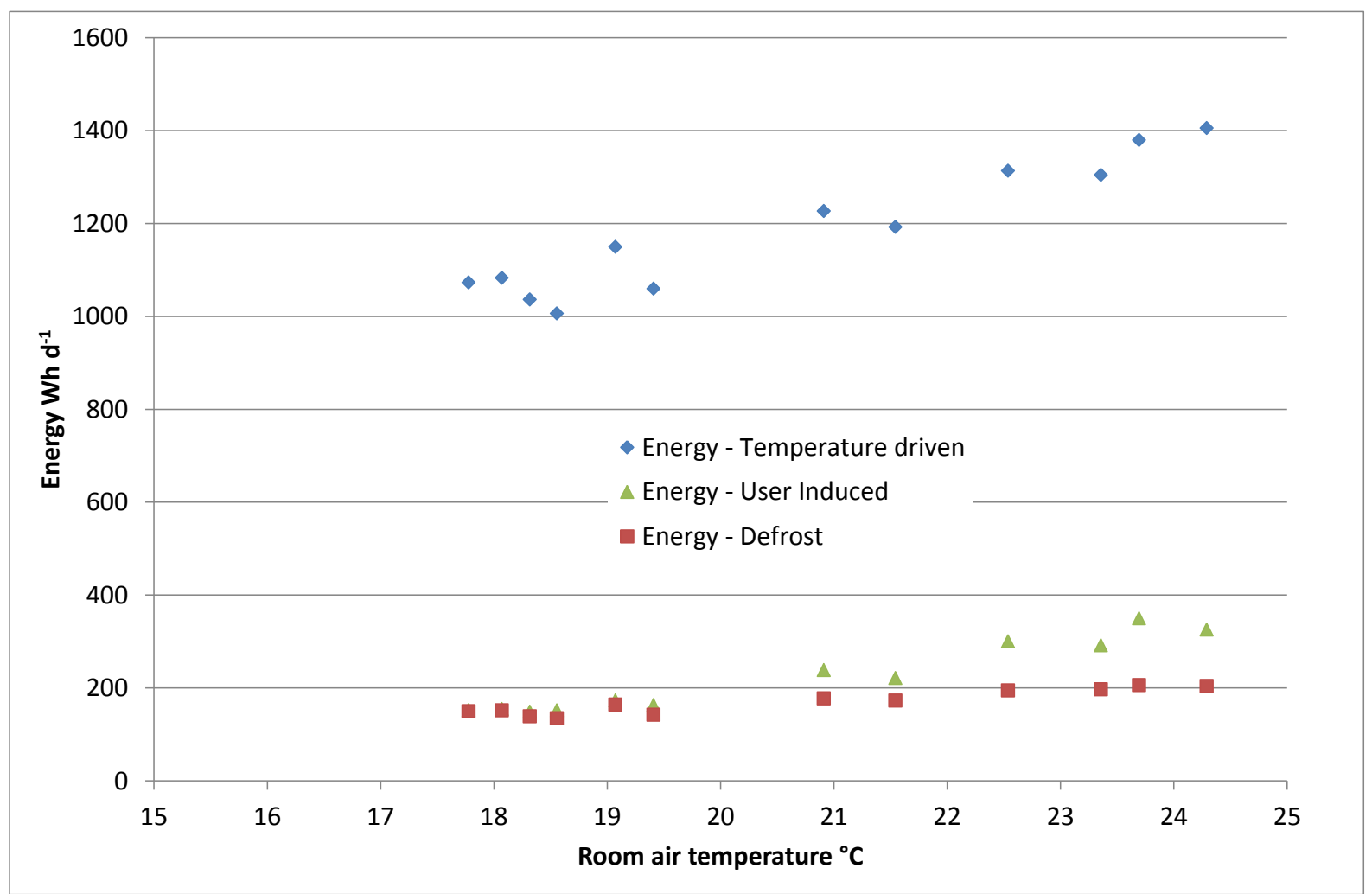

Fig. 11: Average room air temperature versus energy component for 235 appliances (covers all appliances and all periods, Source: Field data collected and analysed by the authors)

Additional analysis was undertaken of the impact of household size on user-induced energy as illustrated in Fig. 12. This shows that induced energy, while quite variable from house to house, is significantly related to household size. Similar analysis also showed that 
defrost energy is also related to household size, but that temperature driven energy is independent of household size (as expected). This simple type of analysis has limitations as climate is clearly a major driver of user-induced energy and Fig. 12 has all climates mixed together (although data in Table 1 suggests the user share should be fairly consistent with climate). A more sophisticated analysis would separate climates or indoor room air temperature as an explanatory variable of user-driven energy consumption. The other limitation is that the user-induced energy is a measure of the additional energy each appliance uses in response to user interactions in that house. This is also dependent on the overall efficiency of the appliance in general, but the load processing efficiency in particular. If, for example, there was a high energy and low energy version of the same sized appliance, a specific set of identical user actions (say door openings and adding specific food or drink to be cooled) would result in different induced energy in each appliance, because the efficiency of extracting this defined latent and sensible heat load would be different. The lower efficiency appliance would appear to have much higher user-induced energy for identical user interactions. This makes the quantitative analysis of user-induced energy consumption somewhat more complex.

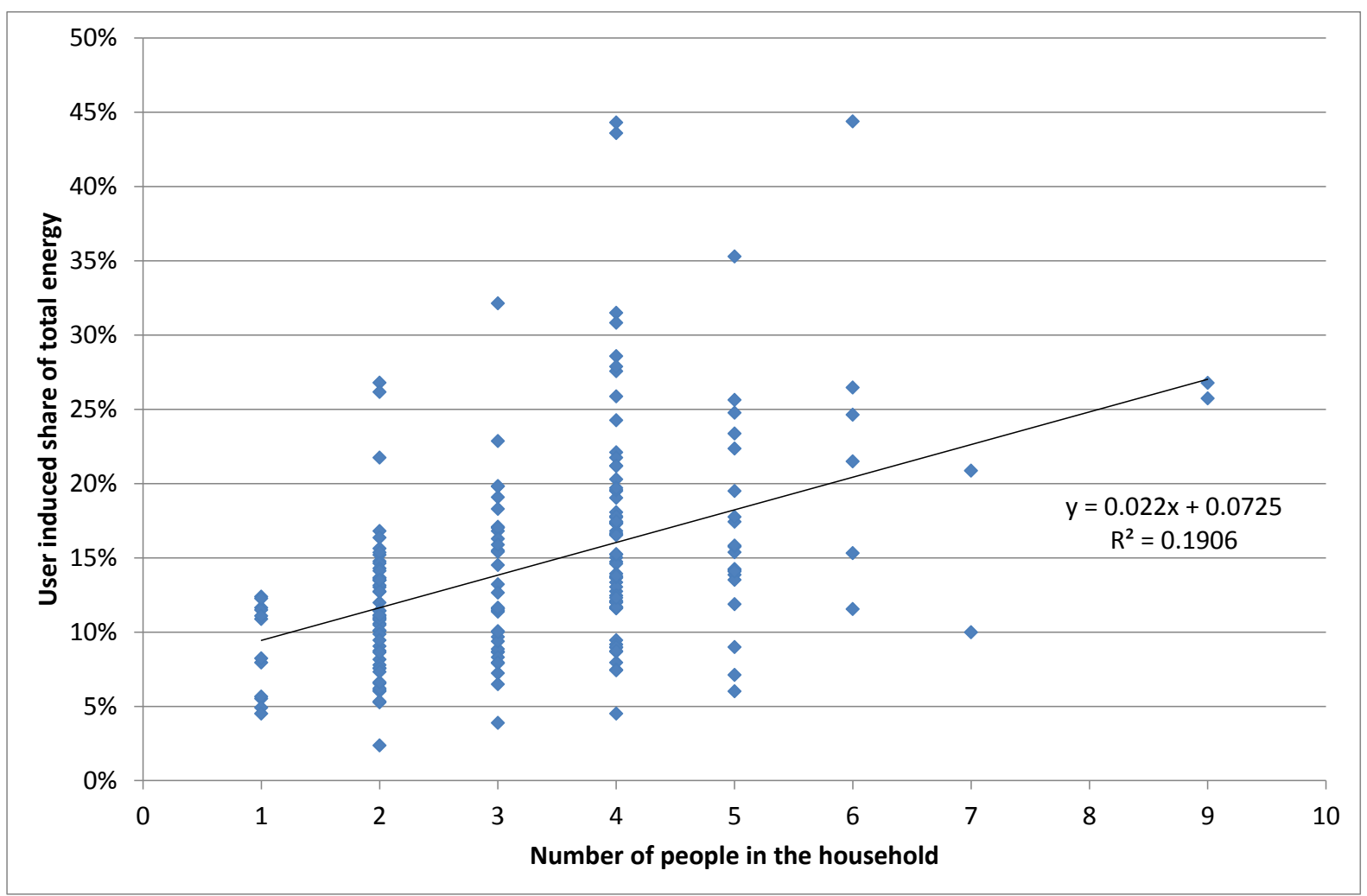

Fig. 12: Share of user-induced energy as a function of household size for main refrigerators for 191 appliances (covers all climates and all periods, Source: Field data collected and analysed by the authors)

This total data set, while substantial, was recorded over a range of different periods, so the results for individual appliances need to be interpreted with care as there is a mix of appliance types, climates, seasons and household sizes included. However, the data still provides a useful insight into energy variations by climate and the stock of appliances in Australia and provides a sound foundation for additional detailed analysis.

\section{Conclusions and outlook}

The analysis undertaken for this paper has generated a rich data set that provides a sound basis for deeper research into understanding the key drivers of energy consumption of 
refrigerators in the home. While the method set out has been developed using energy and temperature data from Australia, the wide range of climates included in the analysis provides a degree of confidence that the approach can be applied to data from any country or region. The key requirement for the application of the method is the collection of high quality energy data and associated room air temperature data over a significant period. A minimum of six weeks of data is recommended. Ideally, data should be collected over a period that allows seasonal effects to be observed. A period of 6-7 months that includes some of winter and some of summer is ideal. To better understand operating conditions in homes, long term regional indoor temperature data in many homes should be used to provide benchmark conditions in each region.

It is also important that as much associated data as possible be collected when appliances are measured in the field. This includes brand and model of the appliance, configuration, any reference data (such as an energy label) and key demographic information such as the number of householders. It is also important to record the location of the appliance and whether it is a primary appliance or a secondary appliance and appliance dimensions.

The method of separating refrigerator energy into its key components set out in this paper provides great insight into the drivers of energy consumption for each appliance when used in a home. The primary objective of this paper is to describe a new method of disaggregating refrigerating appliance energy data measured in the home into its constituent components. This has been successfully applied to 235 appliances in Australia. The steps outlined in this paper are just the beginning of the process of developing greater knowledge and understanding on how refrigerators work in the home. The authors have used the method set out in this paper to undertake a deeper investigation into the response of refrigerating appliance to changes in room air temperature (Harrington et al. 2018b) and to examine defrosting behaviour in the home (Harrington et al. 2018a). An analysis of user interactions as a function of appliance size, household size and climate is also in preparation.

Analysis in this paper shows that room air temperature is the single most important driver of energy usage for household refrigerating appliances, confirming the analysis of many previous authors. On average, ambient temperature accounted for between $75 \%$ and $85 \%$ of the energy consumption of the refrigerating appliances in homes. Automatic defrosting accounted for around $10 \%$ to $11 \%$ of energy where this function was present, while user interactions accounted for between $13 \%$ and $17 \%$ of energy for main refrigerating appliances (less for secondary appliances and separate freezers). The analysis in this paper shows that energy consumption of a refrigerating appliance is very sensitive to room air temperature, as expected. The new IEC test method (IEC62552-3 2015), which measures energy consumption at $16^{\circ} \mathrm{C}$ and $32{ }^{\circ} \mathrm{C}$, provides a much-improved basis for estimating the temperature driven energy component of refrigerating appliances in the home when operating at different room air temperatures. However, this will only be accurate where the temperature-driven part of the energy consumption is estimated for a specific room air temperature. Where there are significant changes in room air temperature over a year, a more accurate assessment could be made by estimating energy for each month, because the response of the refrigerating appliance and user interactions are partly non-linear. A method to use the IEC energy values at $16{ }^{\circ} \mathrm{C}$ and $32{ }^{\circ} \mathrm{C}$ to estimate energy consumption at a given room air temperature over a year is set out in IEC TR 63061 (2017). More in-depth analysis on the issue of using energy data measured under different test methods and converting this to estimated energy at different ambient temperatures is set out in Harrington et al. (2018b). Preliminary analysis in this paper suggests that defrosting energy and user-induced energy all respond at different rates to changes in room air temperature, so an artificial increase in room air temperature to compensate for user interactions during normal use, as has been done previously in many test 
procedures, is unlikely to give very reliable estimates or ranking at an individual appliance level in the home.

Historically, differences in user interaction and room air temperature between houses have confounded the analysis of refrigerator energy data and the lack of understanding of defrost behaviour and responses to changes in room air temperature of individual appliances have made direct comparisons and benchmarking difficult, if not impossible. The approach set out in this paper provides a valuable tool for policy makers and analysts as it allows energy components to be separately identified and quantified and this will assist in the normalisation of energy data across different households and climates. It also breaks total energy consumption into its components that can then be related back to the new IEC test method. This will allow more robust approaches in the prediction of energy consumption of household refrigeration appliances in normal use and will provide a better understanding of how to make future refrigerating appliances more efficient in the home.

\section{References}

Alissi, M. S., Ramadhyani, S., \& Schoenhals, R. J. (1988). Effects of ambient temperature, ambient humidity, and door openings on energy consumption of a household refrigeratorfreezer. ASHRAE Transactions, 94, 1714-1736.

Anjana, H. M. K., Nimarshana, P. H. V., \& Attalage, R. A. Steady state performance variation of domestic refrigerators under different ambient conditions of Sri Lanka. In MERCon 2015 Moratuwa Engineering Research Conference, 2015 (pp. 177-181).

AS/NZS4474.1 (2007). Performance of household electrical appliances-Refrigerating appliances: Part 1: Energy consumption and performance. Sydney: Standards Australia.

Australian Bureau of Statistics (2014). Environmental Issues: Energy Use and Conservation. Canberra.

Australian Consumers' Association (2012). Raw test data for household refrigerators and freezers. Choice (1999 to 2012 ed.). Sydney: Australian Consumers' Association.

Bansal, P. K., Vineyard, E., \& Abdelaziz, O. (2011). Advances in household appliances - A review. Applied Thermal Engineering, 31(17), 13, doi:10.1016/j.applthermaleng.2011.07.023.

Björk, E., \& Palm, B. (2006). Performance of a domestic refrigerator under influence of varied expansion device capacity, refrigerant charge and ambient temperature. [Article]. International Journal of Refrigeration, 29(5), 789-798, doi:10.1016/j.ijrefrig.2005.11.0o8.

Brenner, P. S., \& DeLamater, J. (2014). Measurement Directiveness as a Cause of Response Bias: Evidence From Two Survey Experiments. [Article]. Sociological Methods and Research, 45(2), 348-371, doi:10.1177/0049124114558630.

Dubba, S. K., \& Kumar, R. (2017). Flow of refrigerants through capillary tubes: A state-of-theart. [Review]. Experimental Thermal and Fluid Science, 81, 370-381, doi:10.1016/j.expthermflusci.2016.09.012.

Energy Efficient Strategies (2008). Energy Use in the Australian Residential Sector 1986 - 2020. for the Department of the Environment, Water Heritage and the Arts.

Euromonitor International Ltd (2017). Passport Global Market Information Database. In Euromonitor International Ltd (Ed.). London, United Kingdom.

Gage, C. L. Field usage and its impact on energy consumption of refrigerator/freezers. In ASHRAE Transactions, 1995 (Pt 2 ed., Vol. 101, pp. 1201-1210)

Geppert, J. (2011). Modelling of domestic refrigerators' energy consumption under real life conditions in Europe. Rheinischen Friedrich-Wilhelms-Universität zu Bonn, Bonn.

Geppert, J., \& Stamminger, R. (2009). Relevance of consumer real life behaviour in cold storage on energy consumption. Paper presented at the Energy Efficiency in Domestic Appliances and Lighting (EEDAL), Berlin, 16-18 June 2009

Geppert, J., \& Stamminger, R. (2010). Do consumers act in a sustainable way using their refrigerator? The influence of consumer real life behaviour on the energy consumption of 
cooling appliances. [Article]. International Journal of Consumer Studies, 34(2), 219-227, doi:10.1111/j.1470-6431.2009.00837.x.

Geppert, J., \& Stamminger, R. (2013). Analysis of effecting factors on domestic refrigerators' energy consumption in use. [Article]. Energy Conversion and Management, 76, 794-80o, doi:10.1016/j.enconman.2013.08.027.

GfK Marketing (2017). Major Domestic Appliances - World Market Estimation. In GfK Retail and Technology GmbH (Ed.). Nuremberg, Germany.

Goodson, M. P., \& Bullard, C. W. (1994). Refrigerator/Freezer System Modeling (M. I. E. Dept, Trans.). Air Conditioning and Refrigeration Center, University of Illinois at UrbanaChampaign.

Greenblatt, J., Hopkins, A., Letschert, V., \& Blasnik, M. (2012). Energy use of US residential refrigerators and freezers: function derivation based on household and climate characteristics. Energy Efficiency, Vol. 6( Issue 1), 28, doi:DOI 10.1007/s12053-012-9158-6.

Grimes, J. W., Mulroy, W., \& Shomaker, B. L. (1977). Effect of usage conditions on refrigeratorfreezer and freezer energy consumption. ASHRAE Transactions, Volume 83 Part 1.

Gupta, J. K., Ram Gopal, M., \& Chakraborty, S. (2007). Modeling of a domestic frost-free refrigerator. [Article]. International Journal of Refrigeration, 30(2), 311-322, doi:10.1016/j.ijrefrig.2006.06.006.

Harrington, L. (2015). Australasian Refrigerator Round Robin: Results of a round robin of six Australasian test laboratories testing four refrigerating appliances to IEC62552-3 in 2013/14 (I. a. S. Department of Industry, Trans.). (pp. 38). Canberra: Department of Industry, Innovation and Science.

Harrington, L., Aye, L., \& Fuller, R. (2015). Characterising indoor air temperature and humidity in Australian homes. Air Quality and Climate Change, 49(4), 21.

Harrington, L., Aye, L., \& Fuller, R. (2018a). Energy impacts of defrosting in household refrigerators: lessons from field and laboratory measurements. [Article]. International Journal of Refrigeration, 86, 480-494, doi:10.1016/j.ijrefrig.2017.12.002.

Harrington, L., Aye, L., \& Fuller, R. (2018b). Impact of room temperature on energy consumption of household refrigerators: Lessons from analysis of field and laboratory data. [Article]. Applied Energy, 211, 346-357, doi:10.1016/j.apenergy.2017.11.06o.

Hermes, C. J. L., \& Melo, C. (2009). Assessment of the energy performance of household refrigerators via dynamic simulation. [Article]. Applied Thermal Engineering, 29(5-6), 11531165, doi:10.1016/j.applthermaleng.2008.06.007.

Hermes, C. J. L., Melo, C., Knabben, F. T., \& Gonçalves, J. M. (2009). Prediction of the energy consumption of household refrigerators and freezers via steady-state simulation. [Article]. Applied Energy, 86(7-8), 1311-1319, doi:10.1016/j.apenergy.2008.10.008.

IEC62552-3 (2015). Household refrigerating appliances - Characteristics and test methods Part 3: Energy consumption and volume. Geneva: International Electrotechnical Commission.

IEC62552 (2007). Household refrigerating appliances - Characteristics and test methods. Geneva: International Electrotechnical Commission.

IEC TR 63061 (2017). Adjusted volume calculation for refrigerating appliances. Geneva: International Electrotechnical Commission.

International Energy Agency (2016). Key World Energy Statistics. (pp. 8o). 9, rue de la Fédération 75739 Paris Cedex 15: International Energy Agency.

Klinckenberg Consultants (2009). Global Carbon Impacts of Energy Using Products. Meersen, Netherlands.

Koa, J. Y., \& Kelly, G. E. (1996). Factors affecting the energy consumption of two refrigeratorfreezers. ASHRAE Transactions, 102 Part 2. 
Market Transformation Programme (2007). Domestic refrigerator test standard vs real-use energy consumption. (Briefing Note BNC11 ed., pp. 9). London: Department for Environment, Food and Rural Affairs, UK.

Masjuki, H. H., Saidur, R., Choudhury, I. A., \& Mahlia, T. M. I. Factors effecting energy consumption of household refrigerator-freezers. In IEEE Region 10 Annual International Conference, Proceedings/TENCON, 2000 (Vol. 2, pp. II-92-II-96)

McNeil, M. A., Letschert, V., \& de la Rue du Can, S. (2008). Global Potential of Energy Efficiency Standards and Labeling Programs (pp. 138). Berkeley, California: Ernest Orlando Lawrence Berkeley National Laboratory.

Meier, A. K. (1995). Refrigerator energy use in the laboratory and in the field. Energy and Buildings, 22, 233-243.

Meier, A. K., \& Heinemeier, K. (1988). Energy use of household refrigerators: a comparison of laboratory and field use. ASHRAE Transactions, 94, 1737-1744.

Meier, A. K., \& Jansky, R. (1991). Field performance of residential refrigerators: a comparison with the laboratory test. Berkeley.

Moretti, F. Refrigeration Energy Label Standard Measurements Linked to Energy Consumption in Daily Use. In P. Bertoldi (Ed.), Energy Efficiency in Domestic Appliances and Lighting (EEDAL), Naples, 2000 (pp. 389-394): European Commission/Springer

Negrão, C. O. R., \& Hermes, C. J. L. (2011). Energy and cost savings in household refrigerating appliances: A simulation-based design approach. [Article]. Applied Energy, 88(9), 3051-3060, doi:10.1016/j.apenergy.2011.03.013.

OmegaWatt (2008). User Manual for the Micrologger. La Faurie, France: OmegaWatt.

Rao, N. D., \& Ummel, K. (2017). White goods for white people? Drivers of electric appliance growth in emerging economies. [Article]. Energy Research and Social Science, 27, 106-116, doi:https://doi.org/10.1016/j.erss.2017.03.005.

Saidur, R., Masjuki, H. H., \& Choudhury, I. A. (2002). Role of ambient temperature, door opening, thermostat setting position and their combined effect on refrigerator-freezer energy consumption. [Article]. Energy Conversion and Management, 43(6), 845-854, doi:10.1016/So196-8904(o1)ooo69-3.

Saidur, R., Masjuki, H. H., Eow, K. F., \& Jamaluddi, M. Y. (2006). Actual usage conditions and energy consumption of refrigerator-freezers. [Article]. International Energy Journal, 7(2), $103-124$.

Saidur, R., Masjuki, H. H., Hasanuzzaman, M., \& Kai, G. S. (2008). Investigation of Energy Performance and Usage Behavior of Domestic Refrigerator Freezer Using Clustering and Segmentation. Journal of Applied Sciences, 8, 3957-3962, doi:10.3923/jas.2008.3957.3962.

Sidler, O., Waide, P., \& Lebot, B. (2000). An Experimental Investigation of Cooking, Refrigeration and Drying End-uses in 100 Households. Paper presented at the American Council for an Energy Efficient Economy, Asilomar, California, August 2000

Steg, L., \& Vlek, C. (2009). Encouraging pro-environmental behaviour: An integrative review and research agenda. [Article]. Journal of Environmental Psychology, 29(3), 309-317, doi:10.1016/j.jenvp.2008.10.004.

Sustainability Victoria (2017). Refrigerator Retrofit Trial. Melbourne.

Whitmarsh, L. (2009). Behavioural responses to climate change: Asymmetry of intentions and impacts. [Article]. Journal of Environmental Psychology, 29(1), 13-23, doi:10.1016/j.jenvp.2008.05.003.

Zimmermann, J.-P. (2009). End-use metering campaign in 400 households In Sweden: Assessment of the Potential Electricity Savings. (pp. 344): Enertech, France.

Zimmermann, J.-P., Evans, M., Griggs, J., King, N., Harding, L., Roberts, P., et al. (2012). Household Electricity Survey: A study of domestic electrical product usage in the UK. (pp. 6oo). Milton Keynes, UK: Intertek Testing \& Certification Ltd with Enertech (France). 


\section{University Library}

\section{- M M I N E R VA A gateway to Melbourne's research publications}

Minerva Access is the Institutional Repository of The University of Melbourne

Author/s:

Harrington, L;Aye, L;Fuller, RJ

Title:

Opening the door on refrigerator energy consumption: quantifying the key drivers in the home

Date:

2018-08-01

Citation:

Harrington, L., Aye, L. \& Fuller, R. J. (2018). Opening the door on refrigerator energy consumption: quantifying the key drivers in the home. ENERGY EFFICIENCY, 11 (6), pp.1519-1539. https://doi.org/10.1007/s12053-018-9642-8.

Persistent Link:

http://hdl.handle.net/11343/282838 